\title{
AROMATICS OXIDATION AND SOOT FORMATION IN FLAMES
}

\section{Progress Report}

August 15, 1990 - August 14, 1993

J. B. Howard, C. J. Pope,

R. A. Shandross, and T. Yadav

Department of Chemical Engineering

Massachusetts Institute of Technology

Cambridge, Massachusetts 02139

April, 1993

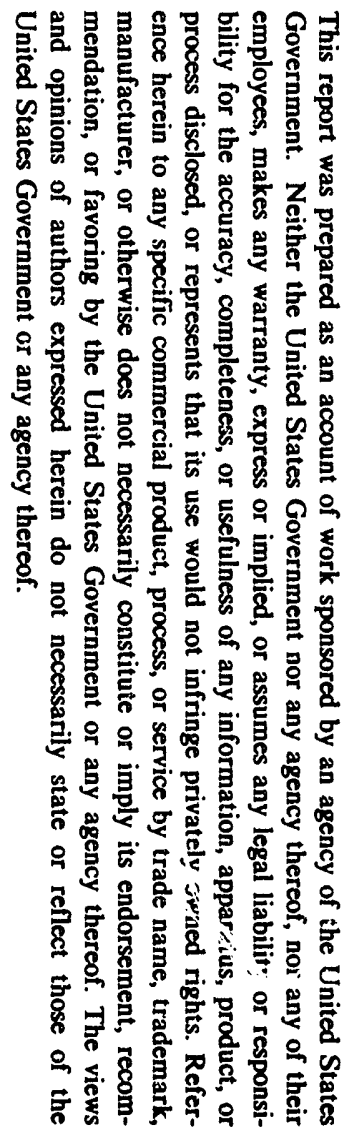

United States Department of Energy Office of Energy Research

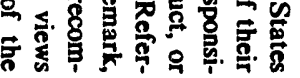
Office of Basic Energy Sciences

Division of Chemical Sciences

Under Contract No. DE-FG02-84ER13282

\section{MASTER}




\section{TABLE OF CONTENTS}

SUMMARY

INTRODUCTION

OBJECTIVES

TECHNIQUES AND EQUIPMENT

5

Aromatics Oxidation Study

Soot Formation Study

6

Fullerenes Formation Study

7

RESULTS

8

Aromatics Oxidation Results

8

Soot Formation Results

Fullerenes Formation Results

CONCLUSIONS

ACKNOWLEDGEMENTS

REFERENCES

PUBLICATIONS FROM THIS PROJECT (1990-1993) 


\section{SUMMARY}

This project is concerned with the kinetics and mechanisms of aromatics oxidation and soot and fullerenes formation in flames. The scope includes detailed measurements of profiles of stable and radical species concentrations in low-pressure one-dimensional premixed flames. Intermediate species identifications and mole fractions, fluxes, and net reaction rates calculated from the measured profiles are used to test postulated reaction mechanisms. Particular objectives are to identify, and to confirm or determine rate constants for, the main benzene oxidation reactions in flames, and to characterize soot and fullerenes and their formation mechanisms and kinetics.

Stable and radical species profiles in the aromatics oxidation study are measured using molecular beam sampling with on-line mass spectrometry. A trace additive technique is used in which benzene in low concentration is studied in a wellcharacterized hydrogen-oxygen-argon flame. In the identification and measurement of the concentration of species expected to be important primary or secondary products of benzene oxidation, phenoxy and cyclopentadienyl radicals do not appear to be present at the detection limit of the equipment. Phenyl radical is present in sufficient concentrations to permit measurement of its concentration profile. Comparison of the phenyl data against predictions from a previous model indicate that either phenyl is not a dominant intermediate in benzene destruction, or the phenyl destruction pathway was inadequately modeled. Also measurable are phenol and cyclopentadiene, the relative concentrations of which in a rich $\mathrm{H}_{2}-\mathrm{O}_{2}$ flame compared to a rich benzene- $\mathrm{O}_{2}$ flame indicate that benzene destruction may differ significantly between these two systems. Several commonly used $\mathrm{H}_{2}-\mathrm{O}_{2}$ combustion models fail to predict well the $\mathrm{O}_{2}$ concentration profile in rich $\mathrm{H}_{2} \mathrm{O}_{2}$ trace benzene flames, possibly indicating inadequate description of the $\mathrm{O}$-atom chemistry.

The rate of soot formation measured by conventional optical techniques is found to support the hypotheses that particle inception occurs through reactive coagulation of high molecular weight $\mathrm{PAH}$ in competition with destruction by $\mathrm{OH}$ attack, and that the subsequent growth of the soot mass occurs through addition reactions of $\mathrm{PAH}$ and $\mathrm{C}_{2} \mathrm{H}_{2}$ with the soot particles. Soot structure indicated by high resolution electron microscopy of collected samples has the appearance of small particles within the roughly spherical units or spherules comprising the soot agglomerates. This structure would be consistent with the growth mechanism inferred from gas phase species if the small internal particles represent reactive coagulation of heavy $\mathrm{PAH}$, and the larger spherules represent coagulation of the smaller particles in parallel with mass deposition from $\mathrm{PAH}$ and $\mathrm{C}_{2} \mathrm{H}_{2}$.

During the first year of this reporting period, fullerenes $C_{60}$ and $C_{70}$ in substantial quantities were found in the flames being studied. The fullerenes were recovered, purified and spectroscopically identified. The yields of $C_{60}$ and $C_{70}$ were then determined over ranges of $c$ )nditions in low-pressure premixed flames of benzene and oxygen. Similar flames with acetylene as fuel were also found to produce fullerenes, but 
in smaller yields than benzene flames. The largest observed yields of $C_{60}+C_{70}$ from benzene/oxygen flames are $20 \%$ of the soot produced and $0.5 \%$ of the carbon fed. The largest rate of production of $\mathrm{C}_{60}+\mathrm{C}_{70}$ was observed at a pressure of 69 torr, a C/O ratio of 0.989 and a dilution of $25 \%$ helium. Several striking differences between fullerenes formation in flames and in graphite vaporization systems include an ability to vary the $\mathrm{C}_{70} / \mathrm{C}_{60}$ ratio from 0.26 to 8.8 (cf., 0.02 to 0.18 for graphite vaporization) by adjustment of flame conditions, and production of several apparent adducts involving fullerenes $C_{60}$, $\mathrm{C}_{70}, \mathrm{C}_{60} \mathrm{O}$ and $\mathrm{C}_{70} \mathrm{O}$, which undergo facile dissociation to the fullerene cage and a hydrocarbon moiety. One such adduct, $\mathrm{C}_{60} \mathrm{C}_{5} \mathrm{H}_{6}$, was isolated and found to be identical to the Diels-Alder adduct of $\mathrm{C}_{60}$ and cyclopentadiene. Fullerenes formation in flames is a molecular weight growth process analogous to the formation of $\mathrm{PAH}$ and soot but involving curved and hence strained structures. A kinetically plausible mechanism of the formation of $C_{60}$ and $C_{70}$ fullerenes in flames has been constructed based on the types of reactions already used in describing PAH and soot growth, but including intramolecular rearrangements and other reactions needed to describe the evolution of the unique structural features of the fullerenes.

\section{INTRODUCTION}

Aromatics play a crucial role in the formation of polycyclic aromatic hydrocarbons and soot in hydrocarbon combustion. The extent of PAH and soot production in a given combustor depends on the balance of formation, destruction and molecular weight growth of the relevant precursors. Although much progress has been made toward understanding important mechanisms in the formation and oxidation of aromatic hydrocarbons, the quantitative predictive capability remains inadequate.

Aromatic components of the fuel and aromatic intermediates in combustion reactions are destroyed in the presence of $\mathrm{O}, \mathrm{OH}, \mathrm{H}$ and other radicals at rates exceeding those estimated for thermal decomposition. Single-reaction studies of benzene oxidation have been carried out but mostly at temperatures lower than flame temperatures. There is much need for measurement under flame conditions of stable and radical reactants, intermediates, and products involved in benzene oxidation.

In the area of soot formation, the long-standing need to describe the overall process in terms of a quantitative predictive model requires knowledge of aromatics oxidation reactions as well as aromatics growth reactions. There is much uncertainty in dealing with both types of reactions. Here again there is need for basic data on the nature and reaction kinetics of the intermediate species, in this case including high molecular weight compounds and different stages of growth.

Following the discovery in the first year of the current contract period that fullerenes can be produced in substantial quantities in the flames being studied, the focus of the work was expanded to include fullerenes formation in combustion. The incremental 
work is complementary to the aromatics and soot studies already underway since fullerenes formation occurs in near-sooting or sooting flames and appears to involve reactions having important similarities to those involved in soot precursor chemistry. Thus, there is need to identify reactants, intermediates and products involved in fullerenes formation, and to determine the mechanisms and kinetics of the reactions involved.

\section{OBJECTIVES}

Responsive to the above research needs, the research reported here is concerned with the kinetics and mechanisms of aromatics oxidation and fullerenes and soot formation in flames. The scope includes detailed measurement of profiles of stable and radical species concentrations and soot-particle number concentration through the reaction and post-flame zones of low-pressure premixed one-dimensional flames. Species identifications and net reaction rates calculated from the profile measurements are used to test postulated reaction mechanisms.

The overall objective of the oxidation work is to study the oxidation of benzene by identifying reaction mechanisms and determining the kinetics properties which vould be consistent with the behavior seen in flames. The specific goals are: (1) to make the necessary measurements of stable and radical species concentrations and temperatures, as functions of distance or time through the reaction zone of simplified low-pressure premixed flat flames, to permit calculation of reaction rates; (2) to gain insight into kinetics and mechanisms from the measured structure of the simplified flames and their base-case analogues; and (3) to test postulated mechanisms of aromatics oxidation against the data.

The objective of the research on fullerenes formation are: (1) to measure the yields of $\mathrm{C}_{60}$ and $\mathrm{C}_{70}$ fullerenes under different flame conditions; (2) to study the kinetics and mechanisms of $C_{60}$ and $C_{70}$ fullerenes formation under combustion conditions; and (3) to identify other fullerenes besides $\mathrm{C}_{60}$ and $\mathrm{C}_{70}$ formed in flames.

The overall objective of the soot formation study is to improve the present model of soot formation by improving the description of (1) the oxidation that competes with growth reactions, and (2) the transition from high molecular weight molecules to nascent soot particles. The molecular to particulate transition is clarified by studying the chemical structure and the growth and destruction rates of high molecular weight material in the particle inception zone of flames.

\section{TECHNIQUES AND EQUIPMENT}

\section{Aromatics Oxidation Study}


The research techniques and equipment are described in detail in the previous progress report (Howard et al., 1990) and will be only summarized here. In the aromatics oxidation study, trace amounts of benzene are added to a low-pressure premixed one-dimensional $\mathrm{H}_{2}-\mathrm{O}_{2}$ flame to ensure that oxidative destruction products are at a sufficiently low level so as not to compete with the oxidants. Detailed profiles of stable and radical species, concentrations, and temperatures, are measured through the reaction zone. Gases are measured by molecular beam sampling with on-line mass spectrometry (MB/MS) supplemented by GC and GC/MS analysis of collected samples. Temperature $i$ is measured using $\mathrm{BeO}-\mathrm{Y}_{2} \mathrm{O}_{3}$ coated $0.076-\mathrm{mm}$ diameter $\mathrm{Pt} / \mathrm{Pt} 13 \% \mathrm{Rh}$ thermocouples (Shandross et al., 1991). An electrical heating method corrects for radiation, except at the highest temperatures, where an estimated emissivity-diameter product is used to solve the heat transfer equation. The base-case flame is also studied in detail, permitting the additive flame to be viewed as a perturbation of the original.

\section{Soot Formation Study}

The research techniques and equipment are described elsewhere (McKinnon and Howard, 1992) and summarized as follows. Laminar premixed flat benzene/oxygen/ argo flames were studied under three sooting conditions: Flame 1: $\phi=2.0,20$ torr, 30\% Ar; Flame 2: $\phi=2.125,40$ torr, 45\% Ar; and Flame 3: $\phi=2.4,40$ torr, 10\% Ar, where $\phi$ is the equivalence ratio or normalized fuel-air ratio. Flame 1 was selected to be similar to the flames studied by Bittner and Howard (1981) $[\phi=1.8$ (almost sooting) and $\phi=$ 1.0]. Flame 3 was selected to provide sufficient soot loadings for optical measurements. The flames were stabilized on a water-cooled, perforated copper plate (12 $\mathrm{mm}$ thick) and surrounded by an annular non-sooting $\mathrm{C}_{2} \mathrm{H}_{4} / \mathrm{O}_{2}$ shield flame for lateral temperature uniformity.

Soot particle size, number density, and volume fraction were measured using standard laser scattering and absorption techniques. The optical properties of soot from Lee and Tien (1981) and a log-normal size distribution were used. Scattering measurements were made at $488 \mathrm{~nm}$ using a 3-W argon-ion laser. Absorption measurements were made in the infrared at $1.4 \mu \mathrm{m}$ to avoid absorption by PAH. Temperatures were determined in the $\phi=2.4$ flame using the brightness-emissivity method.

PAH were measured by sampling gases from the flame using a water-cooled quartz probe with a $0.7 \mathrm{~mm}$ orifice. The bottom $2 \mathrm{~cm}$ of the probe was uncooled to minimize flame perturbation. The pressure inside the probe was 1 torr or less for rapid expansion of the sample in the hot section. The heavier PAH (approximately 3 rings and larger) condensed on the probe walls, while the lighter species were collected in a liquidnitrogen-cooled trap ahead of the vacuum pump. At the end of the run, the sample was extracted in dichloromethane (DCM) for analysis. 
Light PAH (up to about $250 \mathrm{amu}$ ) were identified by gas chromatography using a thick-film capillary column. The total amount of DCM soluble and insoluble material was determined gravimetrically (Lafleur et al., 1986). The upper size limit of the DCMsoluble PAH was estimated by fast-atom bombardment/mass spectrometry to be 900 amu. Light gases were sampled with a similar probe and analyzed with an on-line mass spectrometer.

\section{Fullerene Formation Study}

The combustion system used in the fullerenes formation research includes the same burner referred to above in the description of soot research. The details in the context of the fullerenes studies are given by Howard et al. (1992a). Benzene was the fuel in most of the work, but acetylene was also used successfully. Either pure oxygen or oxygen mixed with argon, helium or nitrogen or some combination thereof, is fed with the fuel.

The burner, in a low-pressure chamber exhausted into a vacuum pump, consists of a horizontal copper plate $(100 \mathrm{~mm}$ diameter and $12 \mathrm{~mm}$ thick, drilled through with 1 $\mathrm{mm}$-diameter holes centered $2.5 \mathrm{~mm}$ apart in a triangular array) upward through which the feed mixture is delivered. The flame is stabilized with a flat front uniformly displaced from the burner plate by a short distance which depends on the velocity of the gas leaving the burner and the flame speed of the mixture. The inner 70-mm diameter section of the burner plate is used for the experimental flame, and the $15 \mathrm{~mm}$ wide outer section is used for an independently fed fuel-rich but nonsooting ethylene/oxygen/inert diluent flame. This annular flame shields the experimental flame, allowing it to approximate a one-dimensional core within which temperature and species concentrations very only with distance, or residence time, from the burner surface, therefy simplifying the mathematical analysis of data.

The fullerenes formation studies have covered different sets of flame conditions over the following ranges: burner chamber pressure, $12-100$ Torr $(1.60-13.35 \mathrm{kPa})$; atomic $\mathrm{C} / \mathrm{O}$ ratio, $0.717-1.082 ; \mathrm{mol} \% \mathrm{Ar}, \mathrm{He}, \mathrm{N}_{2}$, or combinations thereof, $0-50$; and gas velocity at the burner $(298 \mathrm{~K}), 14.6-75.4 \mathrm{~cm} / \mathrm{s}$. The work has included one nonsooting flame, which does form fullerenes, produced under conditions (20 Torr, $\mathrm{C} / \mathrm{O}-0.72,30 \% \mathrm{Ar}$, and $50 \mathrm{~cm} / \mathrm{s}$ ) where soot formation would be impending if the $\mathrm{C} / \mathrm{O}$ ratio were increased by $5 \%$ with the other conditions not changed. Many of the flames were maintained for about 1-3 h, depending upon conditions, while a sample of condensible compounds and soot was withdrawn from the flame at a given distance from the burner using a quartz probe connected to a room-temperature filter, vacuum pump, and gas meter (Howard et al., 1992a). The mass of the sample is primarily that of soot, except at the lowest $C / O$ ratio, where the flame is nonsooting. Soot is also collected from the inside surface of the burner chamber after each run in which a probe sample is taken as well as after many other, exploratory, runs conducted solely for the surface deposited samples. 
Details of the analytical procedures have been published (Howard et al., 1992a). Briefly, the samples of condensed compounds and soot are weighted, extracted with toluene using an ultrasonic bath at room temperature, and filtered. The toluene extracts are analyzed by high performance liquid chromatography (HPLC) using a ternary pumping system and diode-array detector. The HPLC column packing is octadecylsilyl bonded C18 silica. A binary non-aqueous mobile phase of acetronitrile and dichloromethane is used in a gradient elution mode. The mobile phase program consists of a linear increase in dichloromethane concentration from 10 to $100 \%$ in $40 \mathrm{~min}$ with a holding time of $10 \mathrm{~min}$ at $100 \%$. Preparative scale separations were performed with a semi-preparative octadecylsilybonded silica analytical column.

Ultraviolet spectroscopy was conducted with a diode-array spectrophotometer using ultra-pure glass-distilled decahydronaphthalene (decalin) as the solvent in order to ensure adequate dissolution and to maximize pentration into the UV. Pure $\mathrm{C}_{60}$ and $\mathrm{C}_{70}$ fullerenes were collected by HPLC and concentrated by evaporation under a stream of nitrogen. The concentrated fullerene solutions (in HPLC solvent) were exchanged into decalin by adding a measured volume to the fullerene solution and evaporating under a stream of nitrogen until the volatile HPLC mobile phase evaporated leaving the highboiling decalin.

Electron impact mass spectra were obtained for fullerenes samples isolated by preparative HPLC and concentrated and evaporated to dryness in a suitable probe vessel using a vacuum centrifuge. Mass spectra were acquired as the direct injection probe was being performed (Anacleto et al., 1993).

\section{RESULTS}

\section{Aromatics Oxidation Results}

Profiles of several species mole fractions and temperature have been measured in. a laminar, premixed $\mathrm{H}_{2}-\mathrm{O}_{2}-\mathrm{C}_{6} \mathrm{H}_{6}$ flame. The flame conditions were $\phi=1.79,31.3 \% \mathrm{Ar}$, $\left(\mathrm{x}_{\mathrm{C} 6 \mathrm{H} 6} / \mathrm{x}_{\mathrm{H} 2}\right)_{\mathrm{o}}=0.01, \mathrm{P}=22$ torr, $\mathrm{v}_{\mathrm{o}}=101.3 \mathrm{~cm} / \mathrm{s}$, where $\phi$ is equivalence ratio, $x_{i}$ is mole fraction of component $i, \mathrm{P}$ is pressure, $\mathrm{v}$ is gas velocity, and suscripts $o$ refer to initial or burner-plate values. Profiles for the major species $\mathrm{H}_{2} \mathrm{O}, \mathrm{H}, \mathrm{CO}_{2}, \mathrm{C}_{2} \mathrm{H}_{2}$, and $\mathrm{CH}_{4}$ have not yet been measured, so the mole fraction of argon cannot be computed. Therefore, the measured ratios $x_{i} / x_{A r}$ were converted to the more absolute quantities $x_{i} / x_{A r 0}$ by the formula:

$$
\frac{x_{1}}{X_{A x_{0}}}=\frac{x_{1}}{X_{A r}} \times\left(\frac{X_{A r}}{x_{A r_{0}}}\right)_{\text {model }}
$$

where $\left(\mathrm{x}_{\mathrm{Ar}} / \mathrm{x}_{\mathrm{Ar} 0}\right)_{\text {model }}$ refers to the value calculated by the semiglobal model of Jackson and Laurendeau (1987). The model-predicted ratio $\mathrm{x}_{\mathrm{Ar}} / \mathrm{x}_{\mathrm{ArO}}$ was found to be consistent 
with the measured ratio $I_{A r} / I_{A r 0}$ multiplied by $A(z)$, the area expansion ratio. The $A(z)$ used was that of Bittner (1981). A new area ratio will ultimately have to be measured for this very different flame to make accurate comparisons with models, but the sensitivity of the results to $A(z)$ is low enough that observations may be made now.

Unlike in the previous flames with low $\mathrm{H}$ and $\mathrm{H}_{2}$ content, the mass discrimination factors $\left(\alpha_{1, A r}\right)$ for this burner of species other than $\mathrm{H}_{2}$ are sensitive to density and composition. To account for the density effect, the $\alpha_{i, A r}$ were measured at several different burner chamber pressures which span the range of densities found in the flame. The mass discrimination factors thus measured fit the form $\alpha_{i, A r}=\left[a^{*} \ln \left(b / T_{\text {flame }}\right)\right]^{-1}$ well. The effect of composition on the calibration factor was estimated by measuring $\alpha_{i, A}$ for two mixture compositions: one approximating the feed, and the other the post-flame zone composition. The values used were linear interpolations between the two, based on the height above burner (HAB).

Temperature was measured with a $\mathrm{Pt}-\mathrm{Pt} 13 \mathrm{Rh}$ thermocouple, coated with $\mathrm{BeO}-\mathrm{Y}_{2} \mathrm{O}_{3}$ ceramic to reduce catalytic heating (Bittner, 1981; Shandross et al., 1991). A modified wire configuration was employed which reduced thermocouple sag - hence conduction error - during measurement. Radiation compensation by electric heating was used up to a flame temperature of about $1640 \mathrm{~K}$. This value and all other reported temperatures are given as corrected for probe effects; $T_{\text {corrected }}=T_{\text {uncorrected }}-100$ (Biordi et al., 1974). The entire temperature profile was also shifted by 4.5 wire diameters (Fristrom and Westenberg, 1965). Temperatures above $1640 \mathrm{~K}$ were estimated by assuming that $h / \varepsilon \sigma$ (where $h$ is the heat transfer coefficient, $\varepsilon$ is thermocouple emissivity, and $\sigma$ the StephanBoltzmann constant) is constant, and equal to the value calculated by:

$$
\frac{h}{\epsilon \sigma}=\frac{T_{\text {unhoated }}^{4}-298^{4}}{T_{\text {flame }}-T_{\text {unhoated }}}
$$

averaged at the two highest temperatures. This assumption was tested for other flames measured with this burner and was found to give temperatures within $\pm 50 \mathrm{~K}$, generally better. The resulting profile was smoothed in two ranges by fitting to $3^{\text {rd }}$ and $5^{\text {th }}$ order polynomials. For the final high-temperature results, $h$ will have to be calculated from the flame gas composition. Because the calibrated species profiles are a function of temperature (through $\alpha_{i, A_{r}}$ ), an iterative process will be used. Convergence is expected in a small number of rounds.

Presented in Fig. 1 are data for $\mathrm{C}_{6} \mathrm{H}_{6}$, which is of course a major species, and the predictions by the Jackson and Laurendeau ("JL") model with different thermodynamics sets and $\mathrm{C}_{2} \mathrm{H}_{2}$ submechanisms, denoted as follows. MMSK refers to the use of the Miller et al. (1983) $\mathrm{C}_{2} \mathrm{H}_{2}$ submodel and $\mathrm{C}_{6} \mathrm{H}_{6}$ the modynamics for $\mathrm{C}_{6} \mathrm{H}_{5}$ and $\mathrm{C}_{6} \mathrm{H}_{7}$ (Jackson and Laurendeau, 1987). MMSKsan is same model as MMSK but with Sandia (Kee et al., 1987) thermodynamics for the $\mathrm{C}_{6}$ radicals. WZ'san is the "reversible Warnatz" $\mathrm{C}_{2} \mathrm{H}_{2}$ mechanism (Westmoreland, 1986; Warnatz, 1983 and 1984) with Sandia thermodynamics. The choice of acetylene mechanisms is discussed below. The temperatures profile is also 
shown.

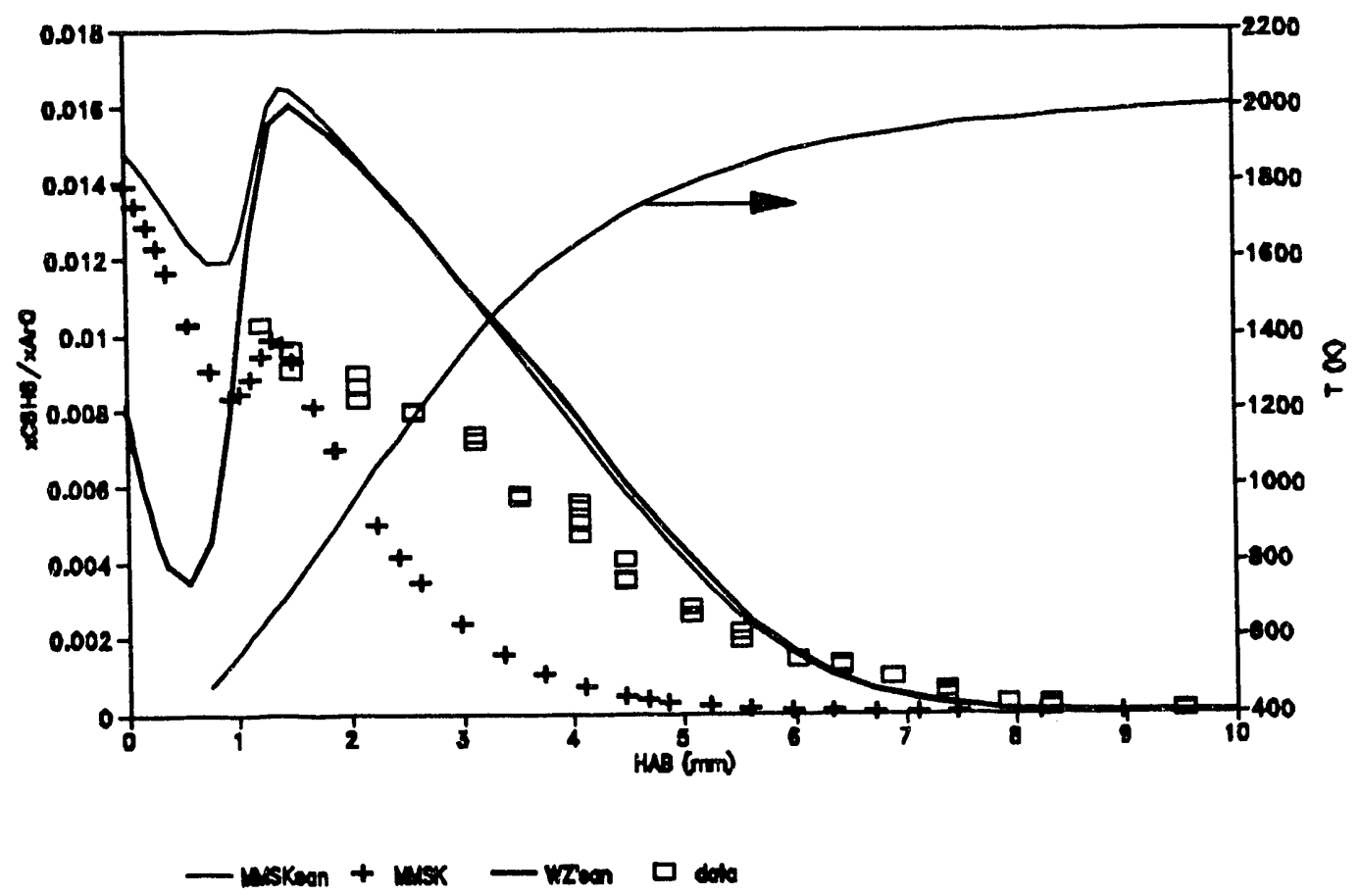

Fig. 1. Mole fraction of $\mathrm{C}_{6} \mathrm{H}_{6}$ (normalized by $\mathrm{x}_{\text {Aro }}$ ), plus calculations from Jackson and Laurendeau model (1987) and measured temperature. See text for notation.

The $\pi$ model was chosen for initial examination because of its developmental purpose for $\mathrm{C}_{6} \mathrm{H}_{6}$ profile prediction. Also, its single-intermediate (phenyl) pathway allows study of the importance of phenyl in benzene oxidation.

Considering the lean conditions under which the model was developed, it does a reasonable job of predicting $\mathrm{C}_{6} \mathrm{H}_{6}$. As can be seen in Fig. $2, \mathrm{H}_{2}$ is also well-predicted. The mass 28 signal was originally assumed to be entirely $\mathrm{CO}$, however more careful measurements of the ionization potential have shown that ethylene is also present. Assuming calibration factors for both species to be identical, about $13 \%$ of the signal was $\mathrm{C}_{2} \mathrm{H}_{4}$ at $3.0 \mathrm{~mm}$ and about $5 \%$ was $\mathrm{C}_{2} \mathrm{H}_{4}$ at $6.0 \mathrm{~mm}$. The reported heights above burner have been corrected for probe effects using $\mathrm{HAB}=\mathrm{HAB}_{\text {unoorrected }}-2.5^{*} \mathrm{~d}_{\text {prober }}$ where $\mathrm{d}_{\text {probe }}$ is the probe orifice diameter (Fristrom and Westenberg, 1965; Biordi et al., 1974). The model prediction for $\mathrm{CO}$ is therefore slightly better than a factor of two. $\mathrm{O}_{2}$ is predicted rather poorly.

The unusual shape of the predicted benzene profiles from the burner to about 1.3 $\mathrm{mm}$ would seem to suggest a numerical artifact, or a problem with the temperature or 


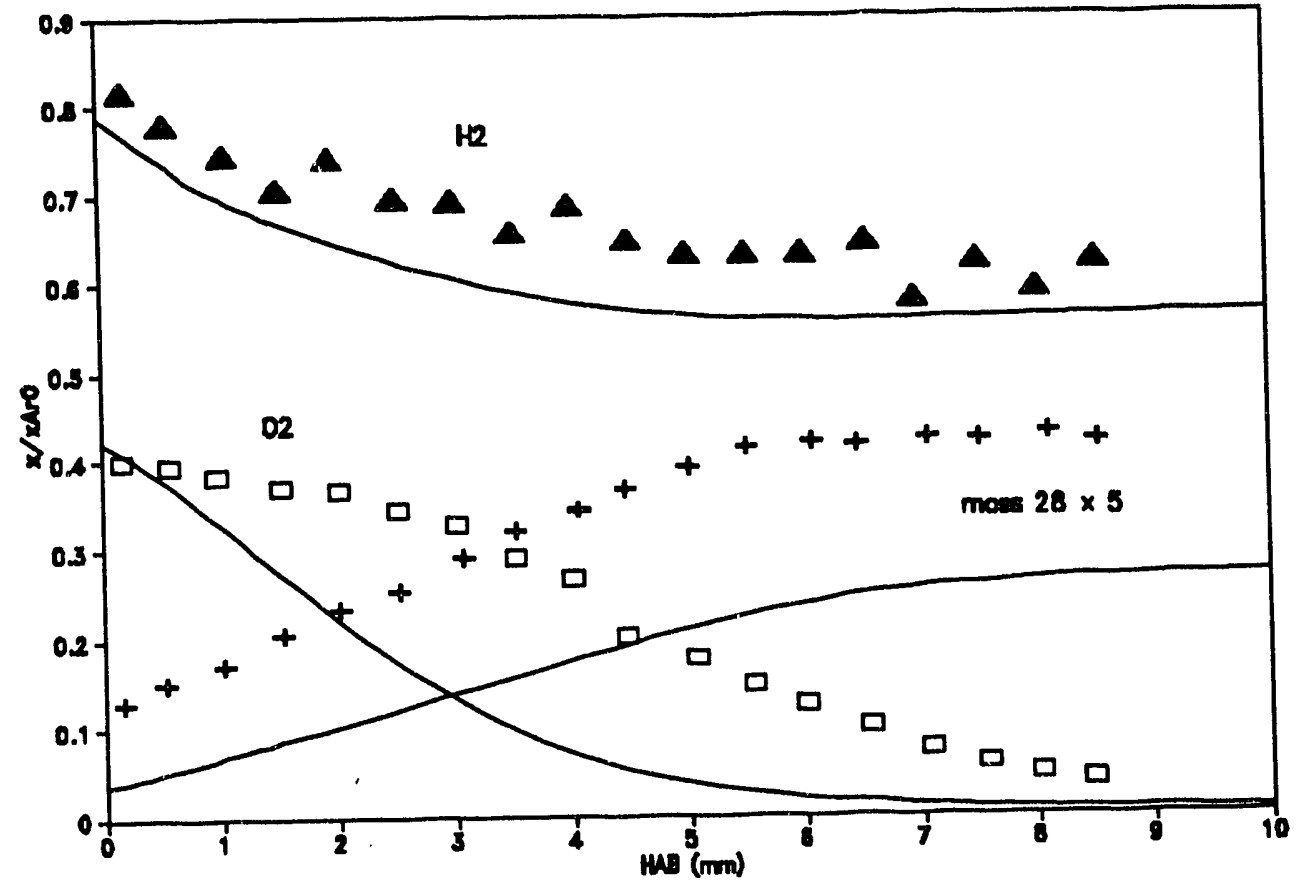

Fig. 2. Data for major stable species $\mathrm{H}_{2}, \mathrm{O}_{2}$ and $\mathrm{CO}$ and predictions of the $\mathrm{JL}$ model (MMSKsan - Jackson and Laurendeau, 1987; Kee et al., 1987).

area expansion ratio. A calculation with $A(z)=1$ gives the same feature, however, thus eliminated $\mathrm{A}(\mathrm{z})$ as the problem. Also, there is no reason to suspect the temperature profile, which has been measured twice. Although we have not performed a formal reaction path analysis, a look at profiles calculated for the other $C_{6}$ species (Fig. 3) reveals the probable cause of the hump. Cyclohexadienyl, formed at low temperatures, ejects its $\mathrm{H}$-atom as the flame gets hotter and quickly re-forms benzene. This is the only pathway available to it. The Warnatz submechanism predicts much more $\mathrm{C}_{6} \mathrm{H}_{7}$ than the Miller mechanism, as a result of the greater amount of $\mathrm{H}$-atom calculated to be present (Fig. 4). The large amount of $\mathrm{C}_{6} \mathrm{H}_{7}$ produces a larger valley in the benzene curve.

We have performed some probing for the presence of $\mathrm{C}_{6} \mathrm{H}_{5}$ and $\mathrm{C}_{6} \mathrm{H}_{7}$ at HABs of $0.85,1.35\left(\mathrm{C}_{6} \mathrm{H}_{7}\right.$ only), 1.7, 3.0, 4.5 and $6.0 \mathrm{~mm}$. Within the scatter of the data, no $\mathrm{C}_{6} \mathrm{H}_{7}$ was found above the isotopic contribution of benzene anywhere in the flame.

Phenyl was essentially not found above $3 \mathrm{~mm}$. Signals were quite scattered, and very close to zero. In fact, due to the low signal-to-noise ratio in both foreground and background counting windows, signals were sometimes less than zero. Measurements 


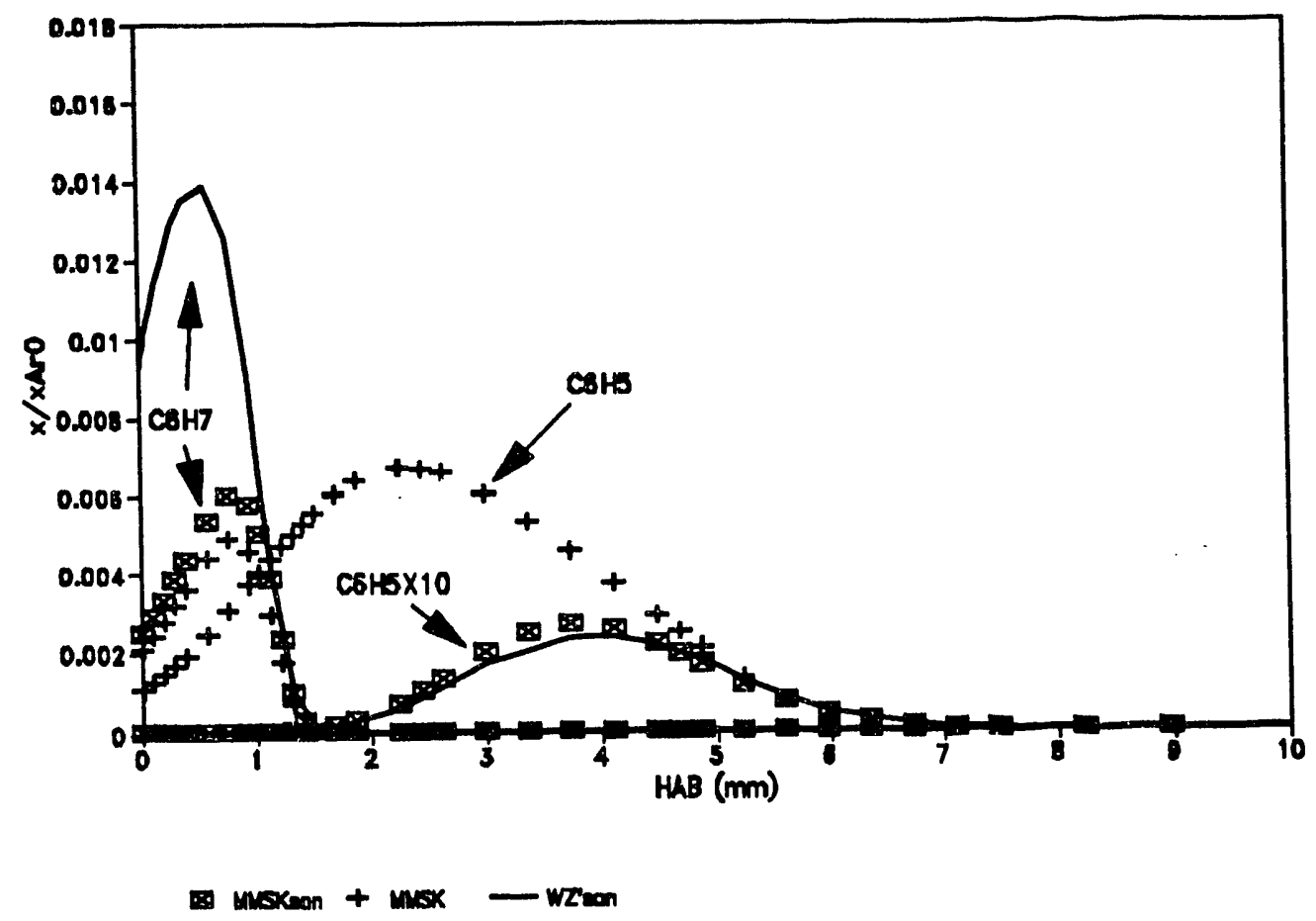

Fig. 3. Predictions of $C_{6}$ species by JL model.

were higher at HABs less than about $3 \mathrm{~mm}$, but the scatter was still large. Phenyl radical may be present in this region, but it is not quantifiable.

Finally, measurements have been made of some other possible intermediates in $\mathrm{C}_{6} \mathrm{H}_{6}$ oxidation. These are shown in Fig. 5. For orientation, the full scale value of this graph is about $41 \mathrm{ppm}$; the peak of the smoothed $\mathrm{C}_{6} \mathrm{H}_{6} \mathrm{O}$ curve would be about $33 \mathrm{ppm}$.

All of the species were measured as $I_{1} / I_{C 6 H 6}$, and "calibrated" using the relative ionization cross-section method (Peeters and Vinckier, 1975; Lazzara et al., 1973). The resulting $x_{i} / x_{\mathrm{C} \mathrm{H} 6}$ were converted to $x_{i} / x_{\mathrm{Ar}}$ by multiplication with $x_{\mathrm{C} 6 \mathrm{H} 6} / x_{\mathrm{Ar}}$ the latter smoothed by fitting to a polynomial in $\mathrm{HAB}$. They were then converted to absolute form $\left(x_{1} / x_{A r 0}\right)$ in the manner described above.

The species of Fig. 5 in greatest concentration is mass 94 , probably phenol, peaking around $5 \mathrm{~mm}$. Next is mass 66 , probably $\mathrm{C}_{5} \mathrm{H}_{6}$, the peak of which is not well-defined. The other species measured are at most slightly above the detection limit of the mass spectrometer. The probe diameter used was $0.59 \mathrm{~mm}$ vs. $0.7 \mathrm{~mm}$ used by Bittner, so the 


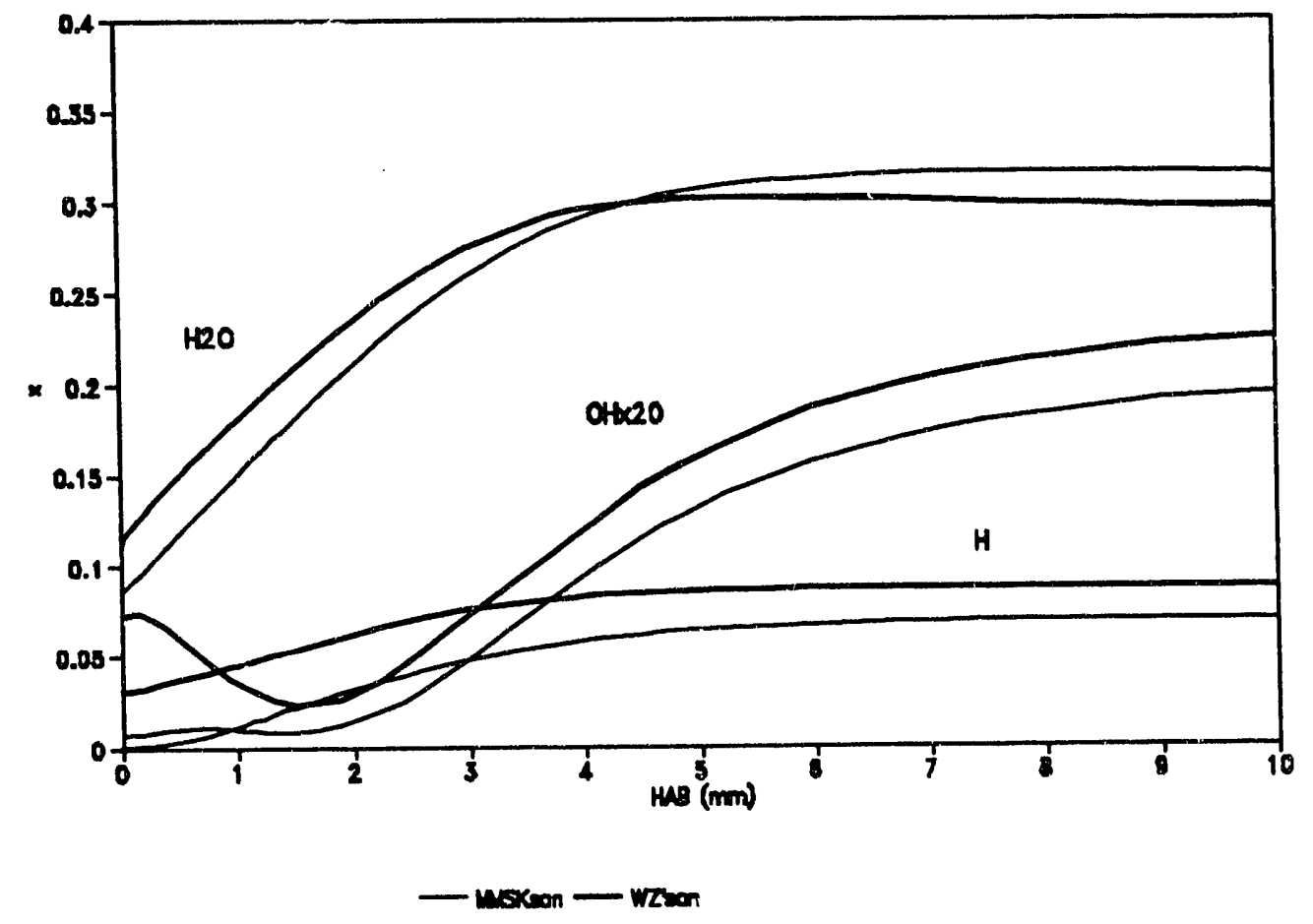

Fig. 4. $\mathrm{H}, \mathrm{OH}$ and $\mathrm{H}_{2} \mathrm{O}$ profiles as predicted by the $\mathrm{JL}$ model.

beam intensity is $0.59^{2} / 0.7^{2}=0.71$ of his. The detection limit is therefore about 1.4 times higher. Deterioration of mass spectrometer performance may make this figure higher. Long pulse counting times (as long as 21 minutes) and multiple measurements were required to acquire these data, but the scatter is still great. Some points represent accumulated counts in the single digits. White noise error alone was large, being on the order of the square root of the number of counts.

Mass 95, if present, would be due to the isotopic contribution of mass 94, instead of being $\mathrm{C}_{6} \mathrm{H}_{6} \mathrm{OH}$ (Fig. 5). The fit here is fortuitous, the scatter and magnitude of the mass 95 data being equal to or slightly better than that of phenyl radical. A more accurate statement would therefore be that mass 95 was not detected above the level of the isotopic contribution of mass 94 .

Phenyl was discussed above. Cyclopentadienyl and phenoxy appear to be below the detection limit (Fig. 6). Several promising intermediate species were detected in general scans at 3.0 and $6.0 \mathrm{~mm}$, but positive identification has not yet been made. 


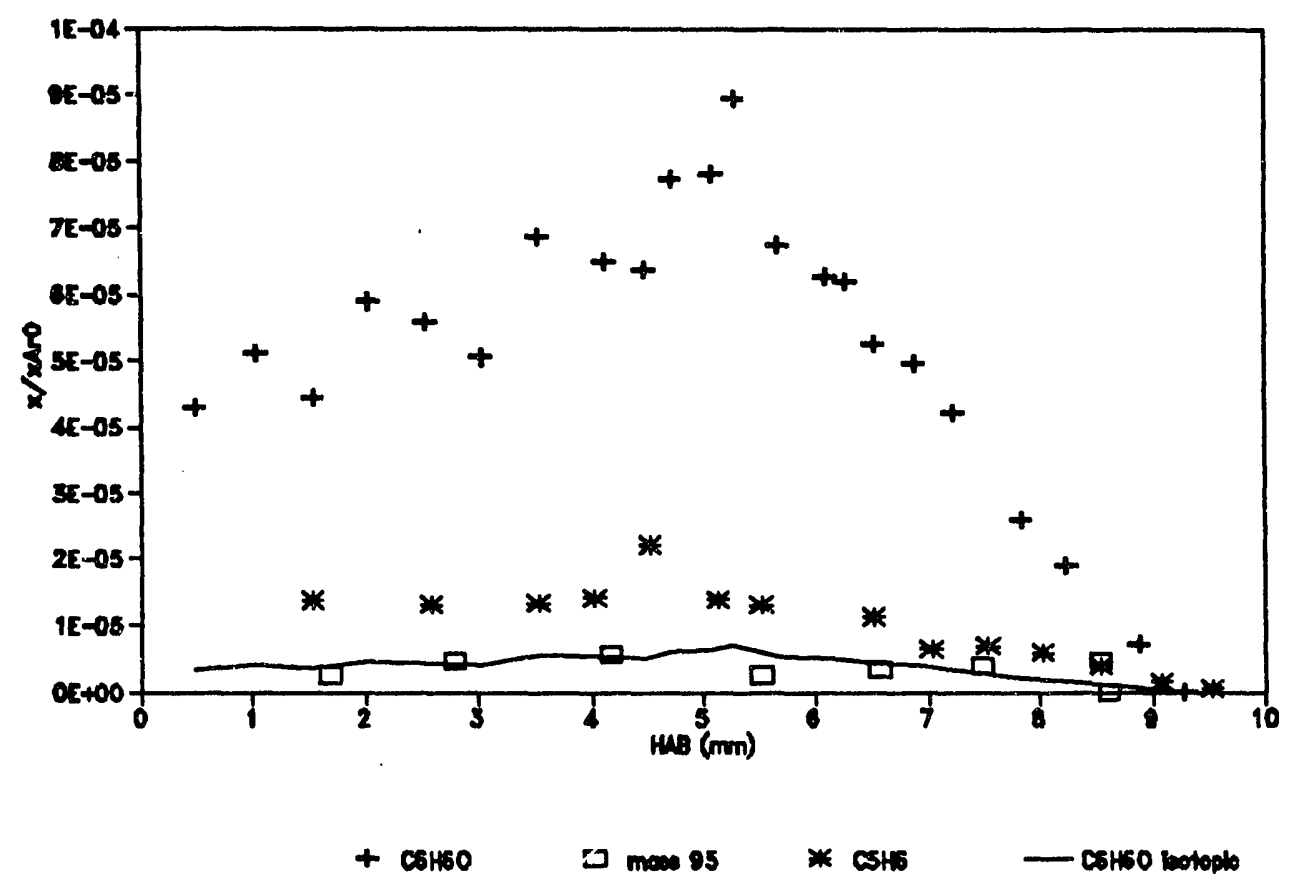

Fig. 5. Aromatics oxidation product data.

The best agreement between the JL model and data was found with molecular hydrogen. Jackson and Laurendeau also saw excellent agreement for $\mathrm{H}_{2}$. The model prediction of significant amounts of phenyl and cyclohexadienyl has not been borne out by the data thus far collected. The species scans at 3.0 and $6.0 \mathrm{~mm}$ were conducted with mass spectrometer tunings that gave much higher (though less accurate) signals. In spite of the greater sensitivity, neither species was found. The model result for $\mathrm{C}_{6} \mathrm{H}_{7}$ is below the detection limit above about $1.5 \mathrm{~mm}$, so not finding $\mathrm{C}_{6} \mathrm{H}_{7}$ there is consistent with the model; however, at $0.82 \mathrm{~mm}$ the model predicts cyclohexadienyl radical to exist at levels ranging from about $50-150 \%$ of the benzene mole fraction, depending on the $\mathrm{C}_{2} \mathrm{H}_{2}$ submechanism used. The model calulates phenyl to be quite plentiful, reaching the easily-measurable value of $250 \mathrm{ppm}$ at about $4 \mathrm{~mm}$. Thus, $\mathrm{C}_{6} \mathrm{H}_{5}$ is poorly predicted.

Correcting the $\mathrm{C}_{6}$ thermodynamics used by Jackson and Laurendeau affects most of the major species very little. However the consumption of $\mathrm{C}_{6} \mathrm{H}_{6}$ and production of $\mathrm{C}_{6} \mathrm{H}_{5}$ are then much slower, as evidenced by the large decrease in phenyl, delayed depletion of benzene, and reduced $\mathrm{CO}$. Acetylene increases in spite of these decreases; one would expect it to decrease because of the semi-global reaction $\mathrm{C}_{6} \mathrm{H}_{5}+\mathrm{O}_{2} \rightarrow 2 \mathrm{CO}+\mathrm{C}_{2} \mathrm{H}_{2}+$ 


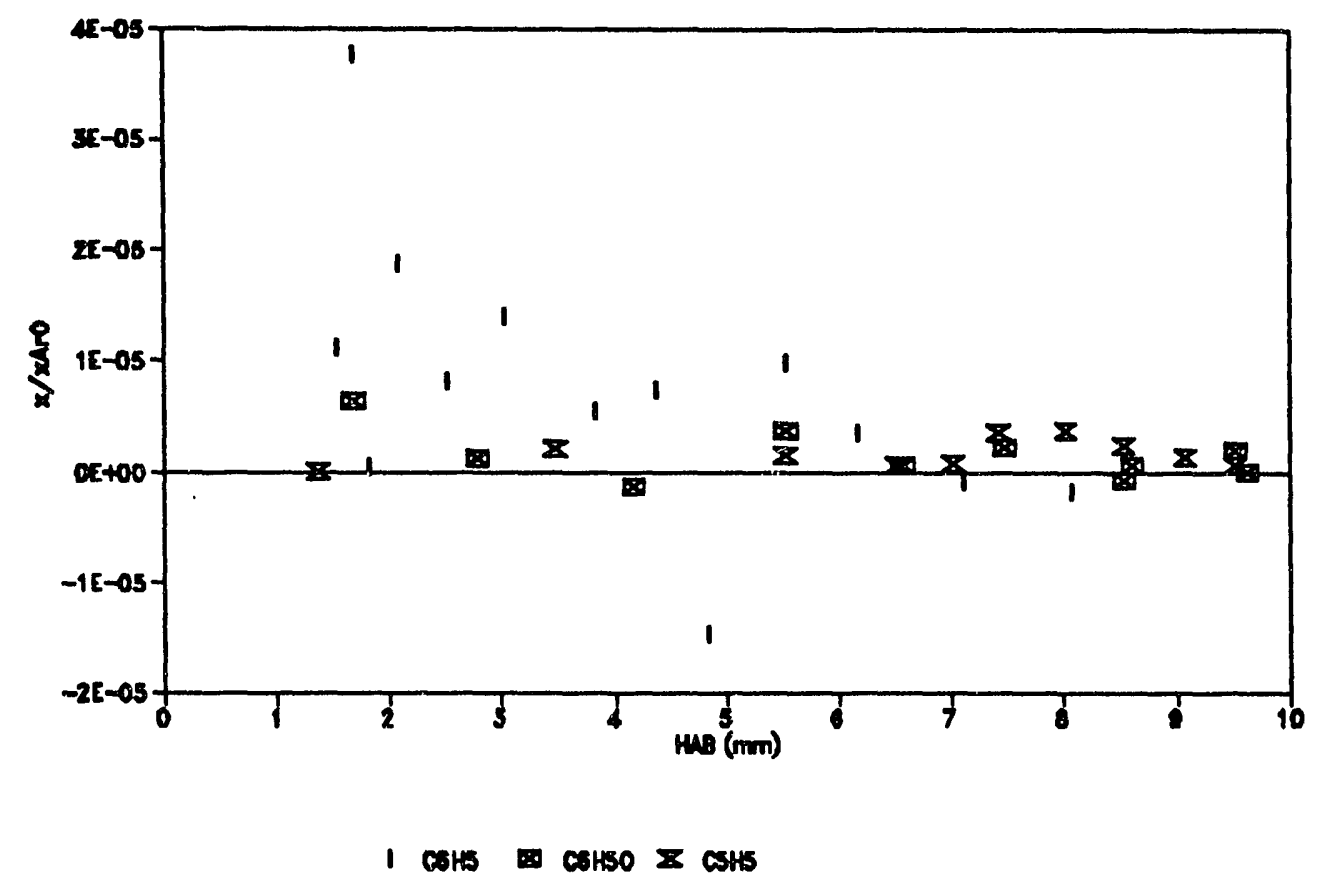

Fig. 6. Possible $C_{5}$ and $C_{6}$ products of benzene oxidation.

$\mathrm{C}_{2} \mathrm{H}_{3}$. The increase in $\mathrm{C}_{4} \mathrm{H}_{3}$ points to greater importance of the phenyl destruction pathway $\mathrm{C}_{6} \mathrm{H}_{5}-\mathrm{C}_{2} \mathrm{H}_{2}+\mathrm{C}_{4} \mathrm{H}_{3}$ as the explanation for this anomaly.

In any event, the absence of $\mathrm{C}_{6} \mathrm{H}_{5}$ suggests that a single-intermediate mechanism centered on phenyl is not adequate to describe benzene destruction in rich $\mathrm{H}_{2}-\mathrm{O}_{2}$ flames. In fact, Jackson and Laurendeau suggest that phenoxy and phenol would be appropriate species to be included in a more complete benzene oxidation model.

Another explanation might be that an important phenyl destruction pathway is missing. Recently, significantly more comprehensive models have been proposed (Chevalier and Warnatz, 1991; Emdee, Brezinsky and Glassman, 1992). These models will be used as starting points for pathway testing in future work.

Calculation of the oxygen profile using only the $\mathrm{H}_{2}-\mathrm{O}_{2}$ chemistry of the model shows that the underprediction of $\mathrm{O}_{2}$ is due exlusively to those reactions. The mass 16 signal in the flame has been examined and determined to be primarily or exclusively $\mathrm{CH}_{4}$, as opposed to O-atom. The model calculates the O-atom concentration to be the same 
order of magnitude as that of $\mathrm{OH}$. Considering the concentrations of various species and the activation energies of the relevant reactions, it appears that (1) one of the important sources of error in the calculated $\mathrm{O}_{2}$ profile is probably the oxygen route $\mathrm{O}_{2}$ $\rightarrow \mathrm{O} \rightarrow \mathrm{OH} \rightarrow \mathrm{H}_{2} \mathrm{O}$, and (2) we expect the $\mathrm{H}_{2} \mathrm{O}$ profile to be overpredicted by the model.

There are several possible explanations for underprediction of $\mathrm{CO}$ by the model. One is problems with the acetylene submechanism. Westmoreland found the MMSK mechanism to give less $\mathrm{CO}$ and more $\mathrm{CO}_{2}$ than he measured, apparently due to the rate constants for $\mathrm{CO}+\mathrm{OH}-\mathrm{CO}_{2}+\mathrm{H}$ and the production of $\mathrm{CO}_{2}$ by reaction of methylene with $\mathrm{O}_{2}$ (Westmoreland, 1986). Also important for the benzene additive flame could be missing oxidation reactions for $\mathrm{C}_{3}-\mathrm{C}_{5}$ species. On the other hand, the WZ' mechanism did a superb job with $\mathrm{CO}$ and $\mathrm{CO}_{2}$ in that flame but its estimate of $\mathrm{CO}$ in the present flame is about the same as the MMSK submechanism. Therefore, the acetylene submechanism may not be at fault.

The CO-producing reaction involving a $\mathrm{C}_{6}$ species in the model is $\mathrm{C}_{6} \mathrm{H}_{5}+\mathrm{O}_{2} \rightarrow 2 \mathrm{CO}$ $+\mathrm{C}_{2} \mathrm{H}_{2}+\mathrm{C}_{2} \mathrm{H}_{3}$. The model's overprediction of phenyl would lead to a calculation of excess $\mathrm{CO}$ instead of the insufficient amount actually estimated. This and the lack of $\mathrm{C}_{6} \mathrm{H}_{5}$ itself suggests instead that the overall $\mathrm{C}_{6}$ chemistry needs a great deal of work.

The predominance of $\mathrm{C}_{6} \mathrm{H}_{6} \mathrm{O}$ and $\mathrm{C}_{5} \mathrm{H}_{6}$ in the present flame is similar to the $\phi=1.8$ benzene flame of Bittner. However, the relative heights of $\mathrm{C}_{6} \mathrm{H}_{6} \mathrm{O}$ and $\mathrm{C}_{5} \mathrm{H}_{6}$ between the two flames are very different. Cyclopentadiene is much more abundant relative to phenol in the rich benzene flame. The reasons for this are not yet clear. As mentioned above, several other species have been detected which could be important intermediates in benzene destruction. Identification of these species is in progress.

\section{$\underline{\text { Soot Formation Results }}$}

Data from the three sets of flame conditions mentioned above (benzene/oxygen/ argon flames at 20 and 40 torr and equivalence ratios 2.0, 2.125 and 2.4) were used, as described elsewhere (McKinnon and Howard, 1992), to study the roles of PAH and acetylene in the nucleation and growth of soot particles. In all the flames, the concentration of high molecular weight $\mathrm{PAH}$ was found to exhibit a maximum value near the onset of soot nucleation and to decline in the nucleation zone. A nucleation mechanism involving growth by reactive coagulation of heavy $\mathrm{PAH}$ in competition with destruction through $\mathrm{OH}$ attack gave good agreement between measured and predicted features of the soot nucleation kinetics. Conversely, soot nucleation through the growth of $\mathrm{PAH}$ by sequential addition of $\mathrm{C}_{2} \mathrm{H}_{2}$ with no PAH-PAH coagulation was too slow to agree with data. PAH also contributed significantly to the post-nucleation growth of soot particles. Most of the mass of the soot system appears to come from $\mathrm{C}_{2} \mathrm{H}_{2}$ through (a) the formation of the heavy $\mathrm{PAH}$ precursors to soot nuclei and the PAH that add to the growing soot particles and (b) direct $\mathrm{C}_{2} \mathrm{H}_{2}$ addition to the soot. Both the growth and 
oxidation reactions in these mechanisms are formulated as involving localized $\sigma$-radicals (i.e., aryl radicals in the case of PAH and active sites in the case of soot). The apparent collision efficiency of PAH with the soot surface is between 0.1 and 0.5 in the region where PAH appears to contribute significantly to the soot mass.

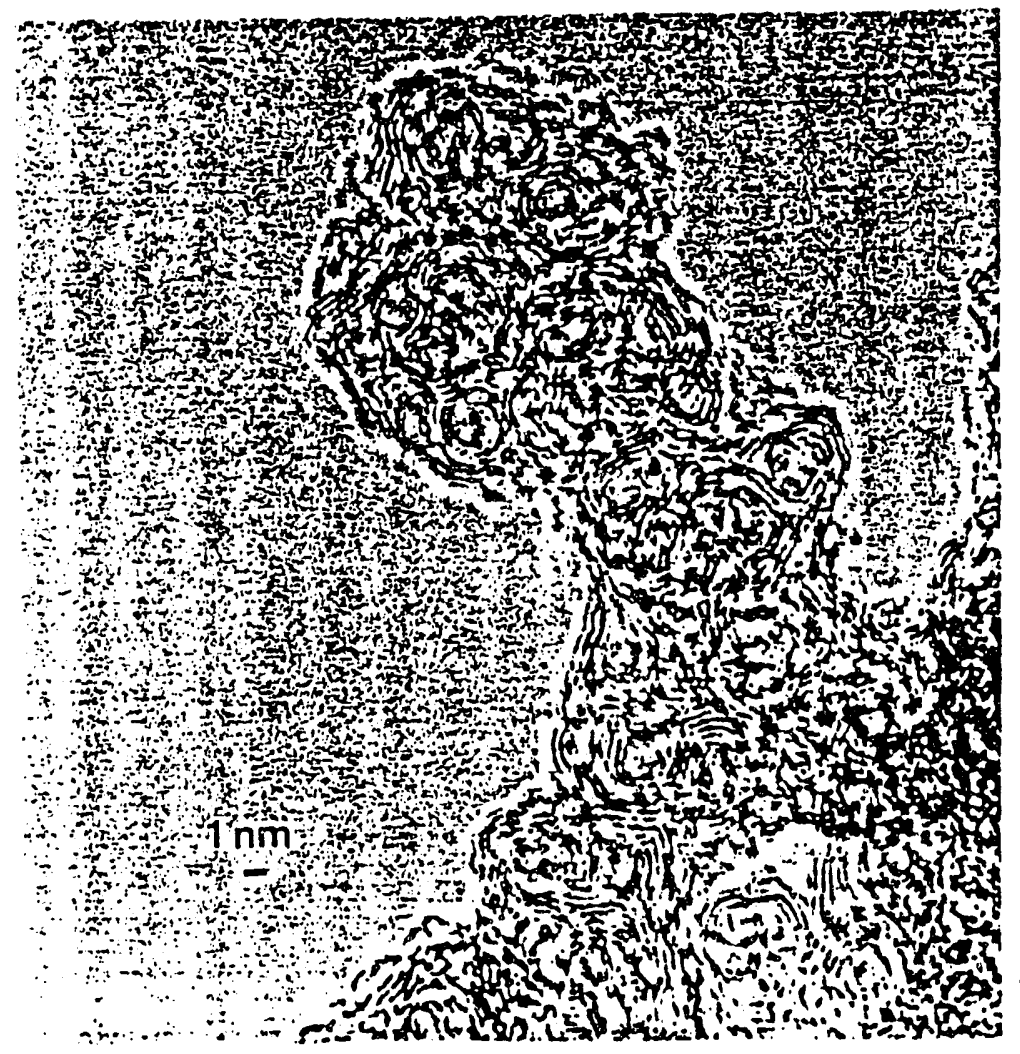

Fig. 7. High resolution transmission electron micrograph of soot from benzene/oxygen/argon flame.

Soot particles collected from the above flames with a quartz sampling probe were analyzed with high resolution electron microscopy. While the quantitative interpretation of the micrographs has not been completed, interesting features of mechanistic significance are apparent. As can be seen in the representative micrograph presented in Fig. 7 , the roughly spherical units comprising the soot aggregates appear themselves to consist of smaller particles, presumably having collided and stuck together simultaneousiy with carbon deposition from gas species. The small particles within the larger particles or spherules aria assumed to be formed from the reactive coagulation of high molecular weight $\mathrm{PAH}$ combined with additional growth from reactions with $\mathrm{C}_{2} \mathrm{H}_{2}$ and PAH. Thus the observed soot structure is consistent with the soot nucleation and growth mechanism found from the analysis of acetylene and PAH data as described above. 
Soot and PAH data from fullerene forming flames were analyzed to determine the order in which PAH, soot and fullerenes appear, which is of mechanistic interest. The results are discussed in the following section.

\section{Fullerenes Formation Results}

\section{Overview}

Results obtained during the first year of this reporting period showed that fullerenes could be produced, and in substantial quantities, in flames (Howard et al., 1991). The initial work has since been reported in more detail (Howard et al., 1992a) and extended to include scoping study of the effects of independent variables on fullerenes yields (Howard et al., 1992b) and identification of novel fullerenes (Anacleto et al., 1992b; Rotello et al., 1993) and study of fullerene formation mechanisms. These results are summarized below.

\section{Identification of $\mathrm{C}_{60}$ and $\mathrm{C}_{70}$ Fullerenes in Flames}

Analysis of the toluene extract of a flame derived soot gave an electron impact mass spectrum (Howard et al., 1991) which compared well with those which had been only recently reported for fullerenes (Kroto et al., 1985; Krätschmer et al., 1990; Taylor et al., 1990; Ajie et al., 1990). Thus the soot sample contained a mixture of $C_{60}$ and $C_{70}$ fullerenes showing molecular ions at $\mathrm{m} / \mathrm{e} 720$ and 840 , respectively, and doubly charged molecular ions at m/e 360 and 420 , respectively. This conclusion was confirmed by Fourier-transform infrared spectroscopy of the soot extract, which gave strong absorption peaks consistent with those reported for fullerenes $C_{60}$ and $C_{70}$.

Although the MS data strongly suggested that fullerenes were the major constituents of the soot, any polycyclic aromatic hydrocarbons (PAH) having molecular weights of 720 or 840 were likely to give the same mass spectra as observed. With improvements in chemical analysis, larger and larger PAH are being observed in combustion samples. Therefore, in order to confirm the above findings, further analysis was performed using high performance liquid chromatography with spectrophotometric diode-array detection (HPLC/DAD). This technique involves the continuous acquisition of UV spectra as peaks elute from the HPLC. The UV spectra of PAH are highly characteristic and can even permit the differentiation of isomeric $\mathrm{PAH}$, a task difficult to achieve by MS. We evaluated a number of HPLC separation schemes for PAH but focused primarily on those shown effective for PAH having upwards of 10 fused rings.

Analysis of toluene extract by HPLC.DAD gave a chromatogram having the striking feature that peaks associated with the typical PAH commonly produced in flames were virtually absent. The two strongest peaks closely matching those published for $\mathrm{C}_{60}$ and $C_{70}$ fullerenes, other peaks present were later found to correspond to $C_{60} O, C_{70} O, C_{76}, C_{84}$, 
$\mathrm{C}_{90}, \mathrm{C}_{94}$ and other fullerenes discussed below.

A full-range ultraviolet-visible (UV-Vis) spectra of the $C_{60}$ and $C_{70}$ peaks, acquired by spectrophotometric analysis of preparative-scale HPLC fractions of the flame sample extract, were observed to be virtually identical to those reported by Ajie et al. (1990) for fullerenes obtained from graphite vaporization. These identifications were confirmed by mass spectral analysis of the HPLC fractions. The $C_{60}$ peak gave a mass spectrum with the reported features of $C_{60}$ fullerene having a molecular ion base peak at $\mathrm{m} / \mathrm{e} .720$, showing no loss of hydrogen and having a doubly-charged molecular ion at $\mathrm{m} / \mathrm{e} 360$. Similarly, the $C_{70}$ peak gave a mass spectrum with features closely matching those of published spectra for $C_{70}$ fullerene showing a molecular ion base peak at m/e 840 and a doubly-charged molecular ion at $\mathrm{m} / \mathrm{e} 420$. These observations established the fullerene assignments beyond doubt. The analytical details are published (Howard et al., 1992a).

\section{Fullerenes $C_{60}$ and $C_{70}$ Yields Under Different Flame Conditions}

The HPLC method described above, including gravimetric calibration of the $\mathrm{C}_{60}$ and $C_{70}$ peaks was used to analyze toluene extracts of flame samples. The yields of fullerenes $C_{60}$ and $C_{70}$ were determined for different flame conditions over the ranges given above, including a not quite sooting flame. Soot mass here refers to the whole sample, consisting of the fraction soluble in toluene, which was largely fullerenes and polycyclic aromatic hydrocarbons, and the toluene insoluble material. The mass of soot or fullerenes expressed as a fraction of the carbon fed is based on the metered volume of flame gas withdrawn with the condensed sample, the known feed rates and burner chamber pressure, and a flame temperature. The calculation of a product yield as a fraction of carbon fed is possible only for samples withdrawn with the probe because the volume of flame gas associated with the collected material is not known for samples removed from the chamber surface.

The detailed results are described elsewhere (Howard, et al. 1992a and 1992b). In summary, the mass of $C_{60}+C_{70}$ produced under the different sooting flame conditions is in the range $0.0026 \%-20 \%$ of the soot mass, compared to $1-14 \%$ from graphite vaporization. The $\mathrm{C}_{60}+\mathrm{C}_{70}$ yield expressed as a percentage of fuel carbon ranges from $2 \times 10^{-4} \%$ for the nonsooting flame to $0.26 \%$ at a pressure of 20 torr, a C/O ratio of 0.996 , $10 \% \mathrm{Ar}$, and a gas velocity at the burner of $49.1 \mathrm{~cm} / \mathrm{s}$. However, larger yields can be estimated as follows from the experiments in which flame samples were collected only from the burner chamber surface. Data from experiments in which both probe and surface samples were collected reveal an approximate relationship between the amounts of soot and fullerenes depositing on the chamber surface and the amounts actually produced in the flame. As can be seen in Fig. 8, the data from the probe samples reveal considerable correlation between the $\mathrm{C}_{60}+\mathrm{C}_{70}$ as a percentage of the carbon fed and the $\mathrm{C}_{60}+\mathrm{C}_{70}$ yield as a percentage of the soot produced. Considering the trend seen in these data in the region of higher yields, the highest $\mathrm{C}_{60}+\mathrm{C}_{70}$ yield of $20 \%$ of the soot, which was deduced from surface samples collected in the multivariable optimization 


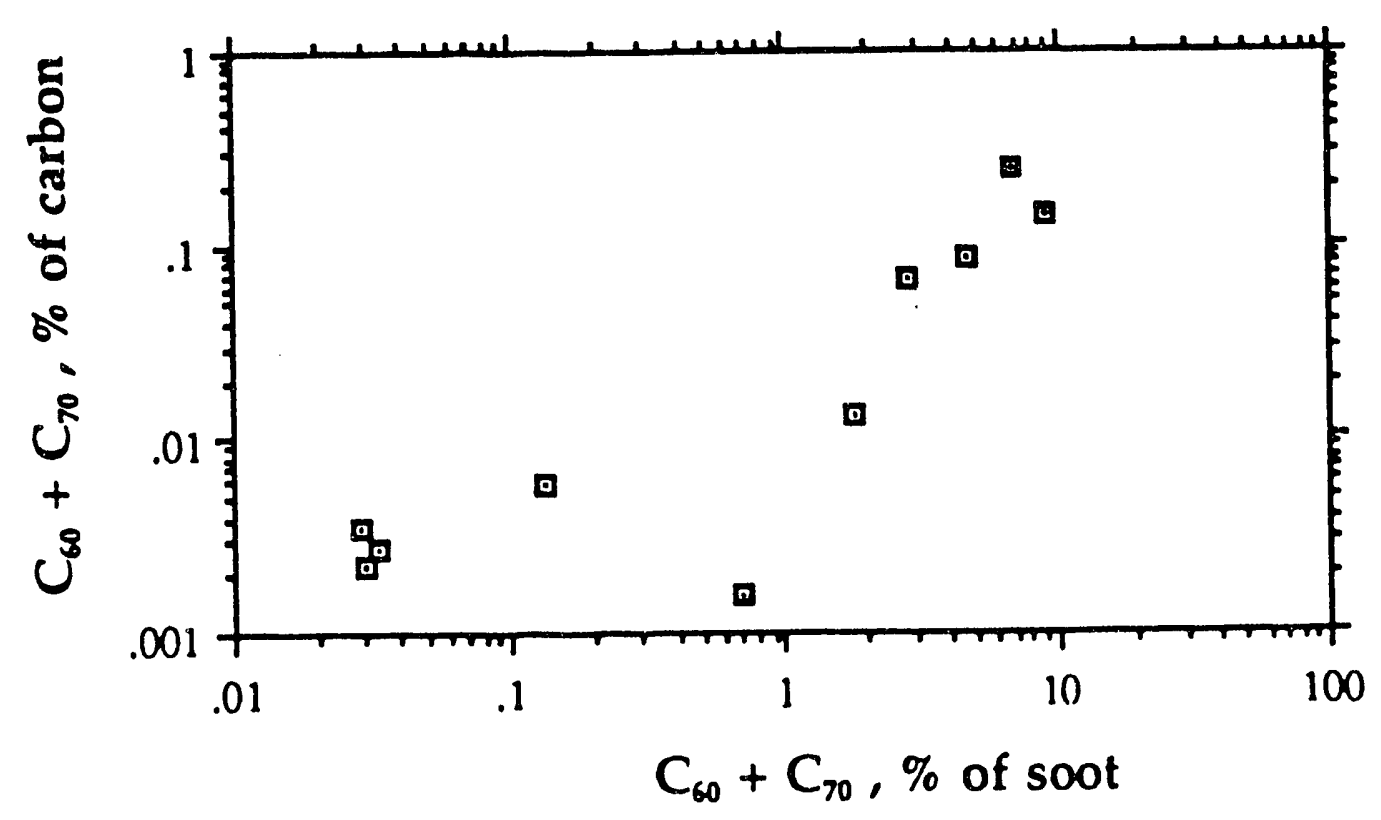

Fig. 8. Yield of $C_{60}+C_{70}$ fullerenes as a percentage of carbon fed and as a percentage of soot, from probe samples.

experiments, would appear to correspond to approximately $0.5 \%$ of the carbon fed. The same conclusion can be reached from Fig. 9 where both the probe sample data and thesurface experiments, would appear to correspond to approximately $0.5 \%$ of the carbon fed. The sample data from the optimization experiments are shown together. Although the data shown on this basis are very scattered, owing to the wide ranges of experimental conditions, the $C_{60}+C_{70}$ yields as a percentage of soot tend to be distributed around a peak at a soot yield of about $1 \%$ of the carbon in the case of the surface samples, and at about 2 to $3 \%$ of the carbon in the case of the probe samples. The implication is that the largest $C_{60}+C_{70}$ yield in the optimization experiments is about 0.4 to $0.6 \%$ of the carbon, essentially the same is the $0.5 \%$ deduced above. Thus the flame synthesis can convert a kilogram of benzene to over 4 grams of $C_{60}+C_{70}$. Given the ability to scale up combustion processes in flow reactors, as for example in carbon black production, flame synthesis of fullerenes would appear to offer potential for large-scale production.

The highest production rate of fullerenes $\left(C_{60}+C_{70}\right)$ in these experiments is $0.45 \mathrm{~g} / \mathrm{hr}$, observed at a pressure of 69 torr, a C/O ratio of 0.989 , a velocity of $38 \mathrm{~cm} / \mathrm{s}$, and $25 \%$ helium. The $\mathrm{C}_{60}+\mathrm{C}_{70}$ mass was $12.2 \%$ of the soot. The variation of $\mathrm{C}_{60}+\mathrm{C}_{70}$ production rate with $C_{60}+C_{70}$ yield as pecentage of soot is illustrated in Fig. 10. The largest $C_{60}+C_{70}$ yield of $20 \%$ of the soot was observed at a pressure of $37.5 \mathrm{torr}$, a C/O ratio of 0.959 , a velocity of $40 \mathrm{~cm} / \mathrm{s}$, and $25 \%$ helium. That the conditions for the maximum $\mathrm{C}_{60}+\mathrm{C}_{70}$ 


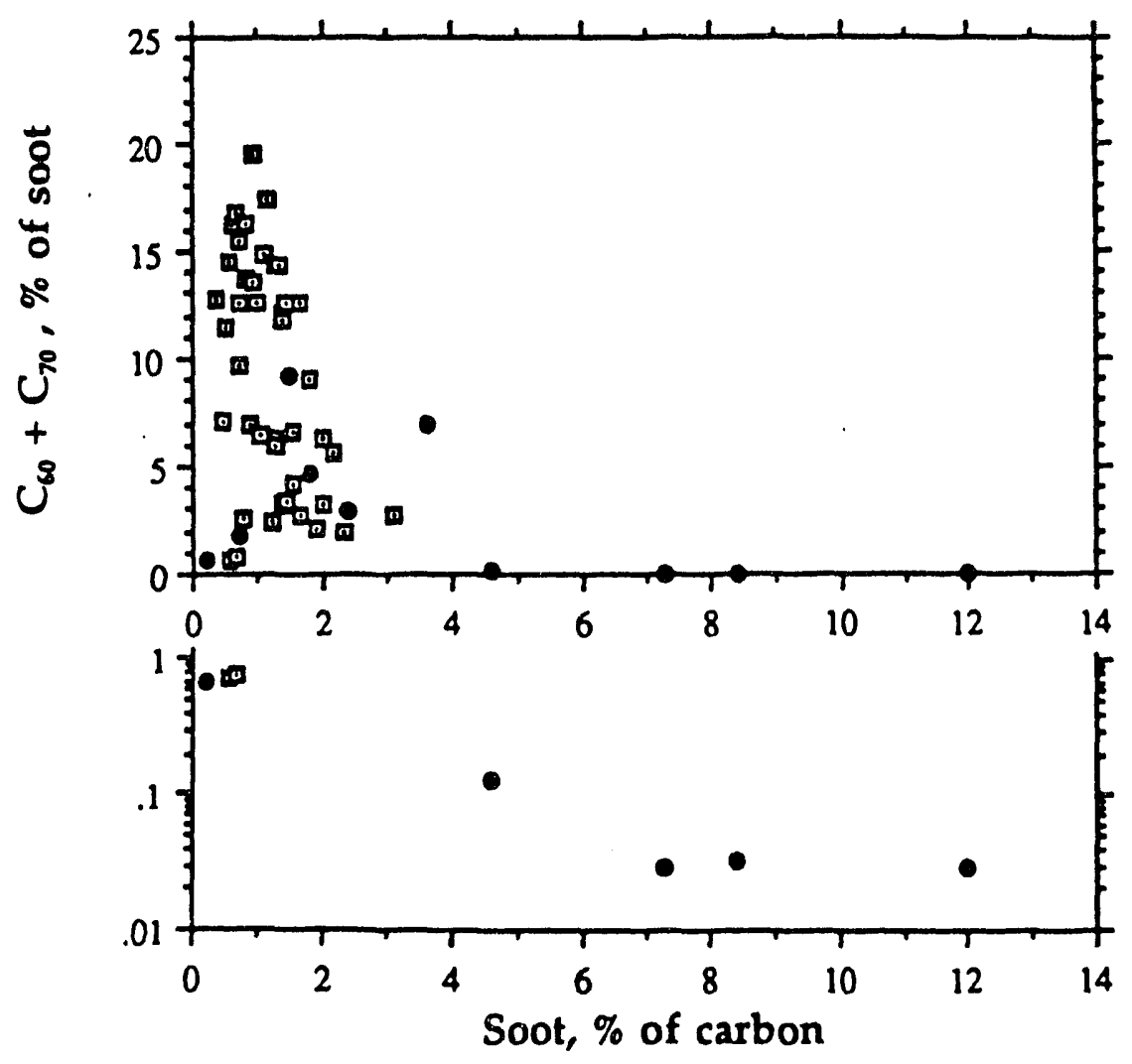

Fig 9. Yields of $C_{60}+C_{70}$ fullerenes and yields of soot, from probe samples $(\bullet)$ and chamber surface deposits $(\square)$. The lower graph is a reproduction of the interval, from the upper graph, $C_{60}+C_{70}=0-1 \%$ of soot.

production rate differ from those for the maximum yield reflects the decrease in yield with increasing pressure under these conditions, which is offset by the increased rate of mass flow through the combustion chamber when pressure is increased at a fixed burner velocity.

The $C_{70} / C_{60}$ molar ratio for the different conditions is in the range 0.26-8.8, compared to $0.02-0.18$ for graphite vaporization. The ratio is 1.5 and 1.8 for the above conditions of largest $C_{60}+C_{70}$ production rate and yield, respectively. The much larger yields of $C_{70}$ and the ability to control the $\mathrm{C}_{70} / \mathrm{C}_{60}$ ratio by setting the flame conditions are significant differences from the graphite vaporization technique. The $\mathrm{C}_{70} / \mathrm{C}_{60}$ ratio tends to be larger under conditions of low $C_{60}+C_{70}$ yields (Fig. 11, part a), low $C_{60}+C_{70}$ production rates (Fig. 11, part b), and lower pressures. For example, the molar $C_{70} / C_{60}$ ratio was 8.8 at 20 torr, $C / O=0.960$, and $50 \mathrm{~cm} / \mathrm{s}$, where the production rate was $1 \%$ of the largest observed value. In contrast, at the same pressure and velocity, but with $C / O=0.996$, the production rate was $60 \%$ of the largest value and the molar $C_{70} / C_{60}$ ratio was 0.88 . To the extent that low yields and low production rates may reflect conditions in some cases close to incipient net fullerene formation, and in other cases close to extensive 


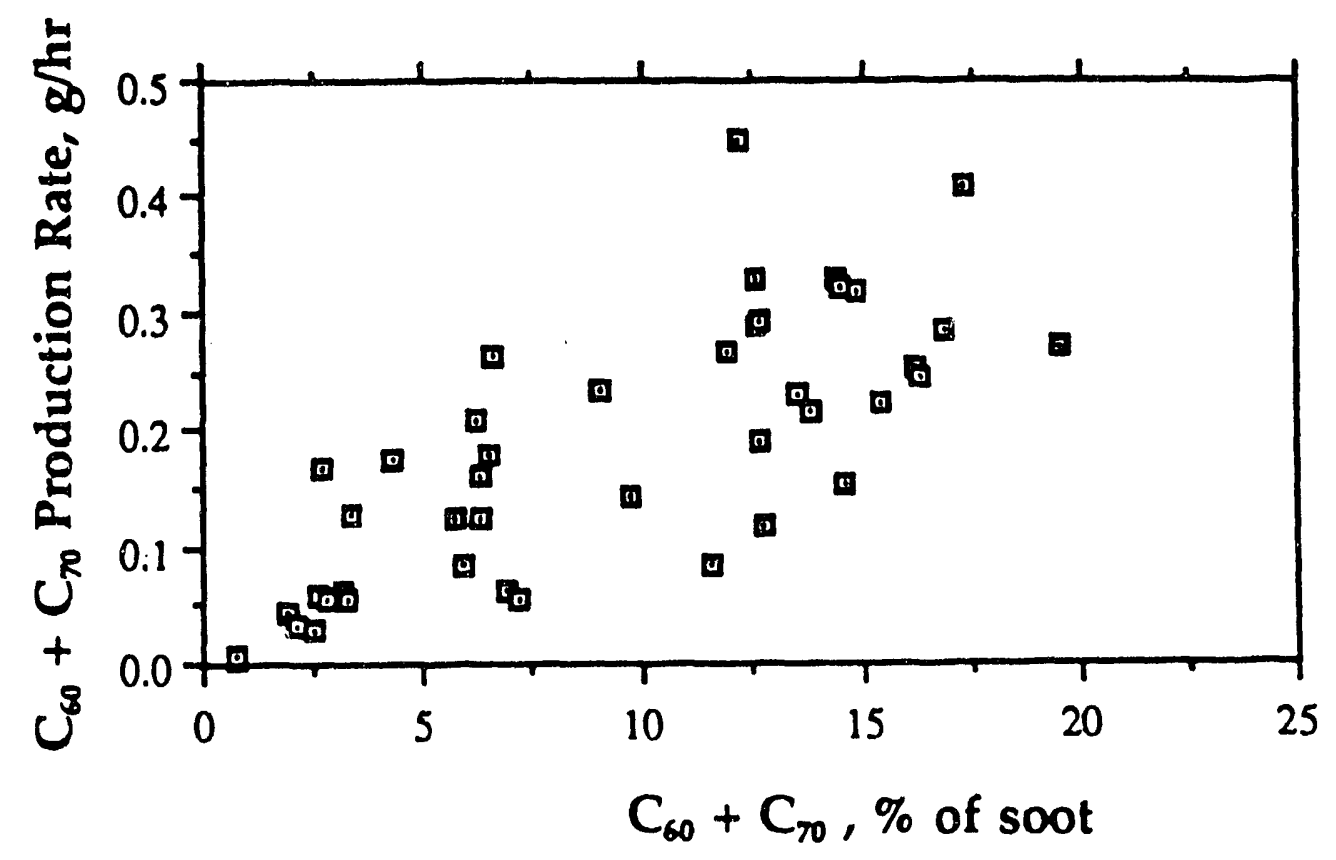

Fig. 10. $C_{60}+C_{70}$ fullerenes production rates and yields, from chamber surface deposits.

destruction of fullerenes already formed, these observations may have mechanistic implications. However, the $\mathrm{C}_{70} / \mathrm{C}_{60}$ ratio only varies by a factor of order 10 while the $C_{60}$ and $C_{70}$ yields each vary by a factor of order $10^{3}$ in these data. Therefore the $C_{70} / C_{60}$ ratio may not be a sharp indicator of mechanistic behavior.

Although the present data clearly identify a window of conditions, i.e., the specified ranges of values of the independent variables, within which fullerenes are formed in flames, the effects of the variables are extensively coupled, and often not easily discerned. For example, the atomic $\mathrm{C} / \mathrm{O}$ ratio, defined as the value of this ratio in the mixture fed to the burner, affects not only species concentrations in the fullerene forming region of the flame, but also the temperature profile, which is strongly dependent on the gas velocity at the burner plate. As shown in Fig. 12, part a, fullerenes yields expressed as a fraction of soot exhibit a maximum as the $C / O$ ratio is increased under conditions of prolific fullerenes formation, but the yields increase monotonically with increasing $C / O$ for less favorable fullerene forming conditions. The $C_{70} / C_{60}$ ratio decreases with increasing $\mathrm{C} / \mathrm{O}$ under both sets of conditions (Fig. 12, part b). All the flames represented here are sooting, the critical $\mathrm{C} / \mathrm{O}$ ratio for the onset of soot formation being 0.76 under these conditions. The increase in $C_{60}+C_{70}$ yield at the lower $C / O$ values 


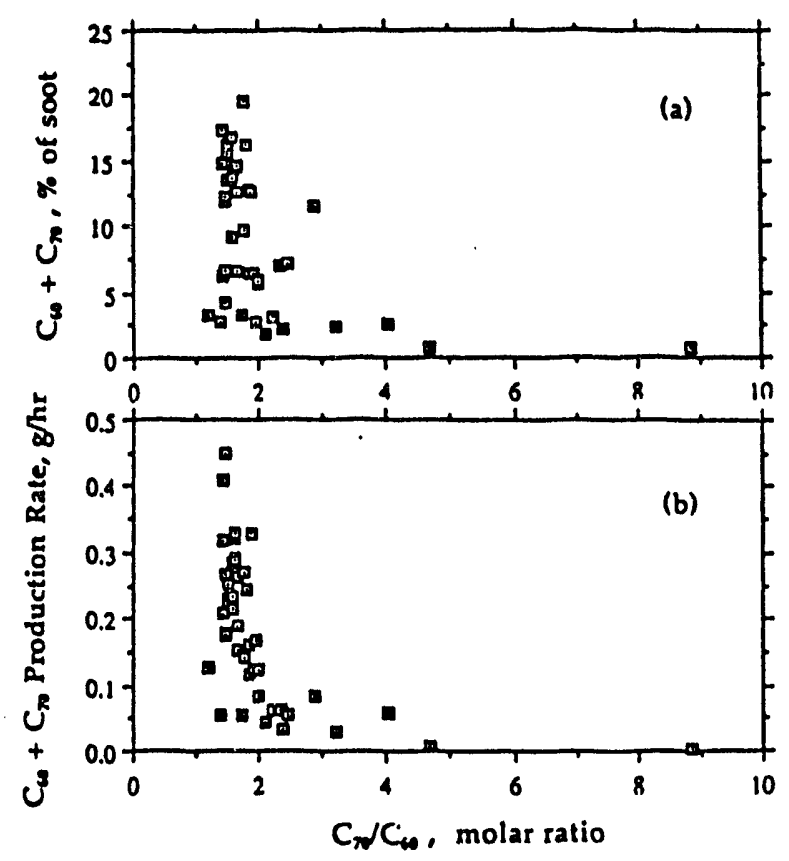

Fig. 11. Fullerenes $C_{70} / C_{60}$ ratios associated with different $C_{60}+C_{70}$ yields (a) and production rates (b), from chamber surface deposits.

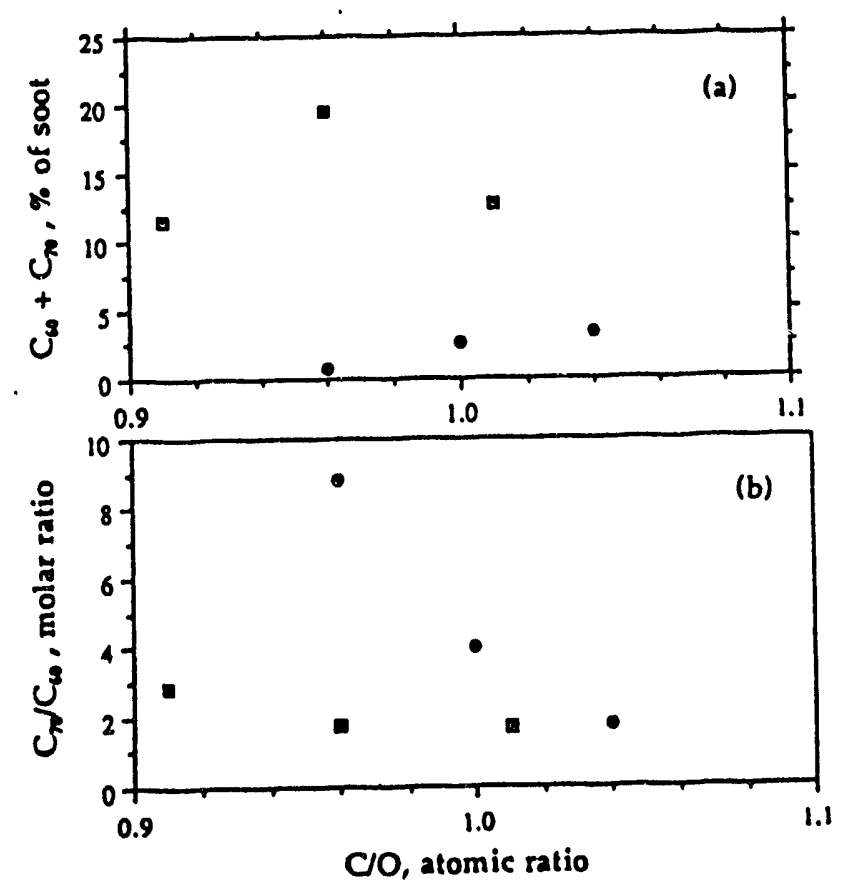

Fig. 12. Effect of $C / O$ ratio on fullerenes $C_{60}+C_{70}$ yield (a) and $C_{70} / C_{60}$ ratio (b) for two sets of flame conditions: (口) 37.5 torr, $40 \mathrm{~cm} / \mathrm{s}$ and $25 \%$ helium; $(\bullet) 20$ torr, $50 \mathrm{~cm} / \mathrm{s}$ and $10 \%$ helium (from chamber surface deposits). 
presumably reflects the higher concentration of reactants for fullerenes growth. The decrease in yield seen at the higher $\mathrm{C} / \mathrm{O}$ value may be the result of lower temperature and slower kinetics. The higher gas velocity results in a higher flame temperature and a capability to go to higher $\mathrm{C} / \mathrm{O}$ values before the negative effect of lower temperature offsets the positive concentration effect.

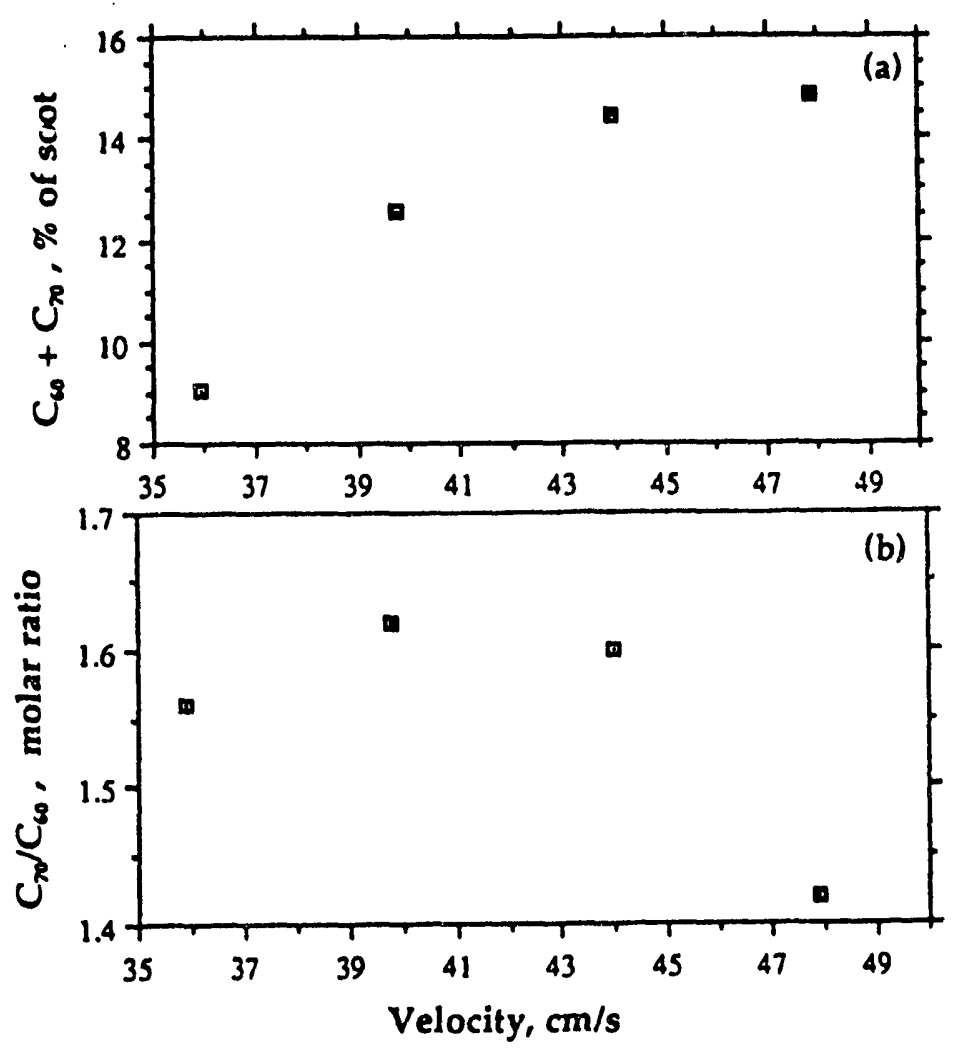

Fig. 13. Effect of gas velocity at the burner on fullerenes $C_{60}+C_{70}$ yield (a) and $C_{70} / C_{60}$ ratio (b) for flames at 40 torr, $\mathrm{C} / \mathrm{O}=0.99$ and $25 \%$ helium, from chamber surface deposits.

The increase of $\mathrm{C}_{60}+\mathrm{C}_{70}$ yield with increasing gas velocity is seen in (Fig. 13, part b). At higher velocities the flame stabilizes farther from the burner and a smaller fraction of the heat is lost into the water-cooled burner plate. The $C_{70} / C_{60}$ ratio (Fig. 13, part b) for this flame exhibits a maximum as the velocity is increased.

The effect of diluent concentration on $\mathrm{C}_{60}+\mathrm{C}_{70}$ yields is shown in Fig. 14, part a, for two flames, one with high and one with low yields. The effect is larger for the low-yield flame, the yield exhibiting a maximum as helium concentration is varied from 10 to $50 \%$. 


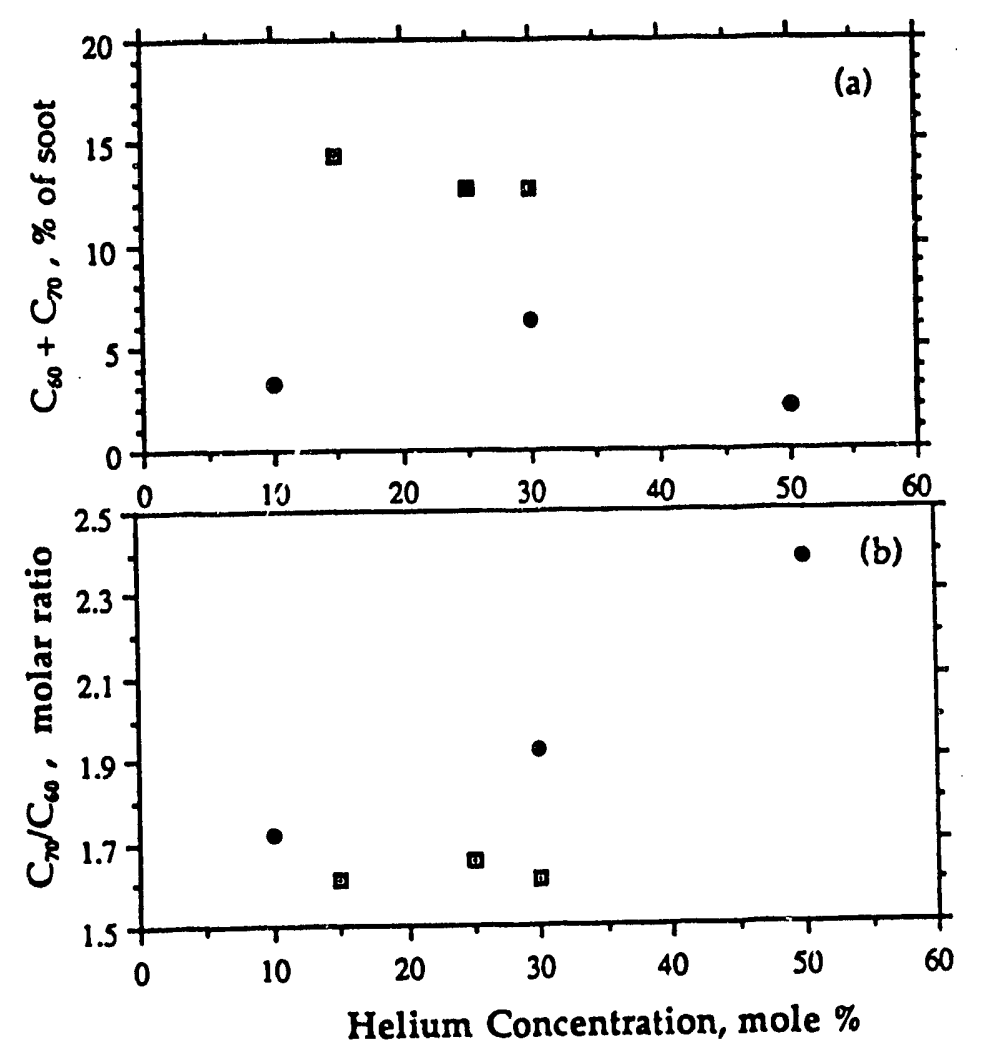

Fig. 14. Effect of diluent helium concentration on fullerenes $C_{60}+C_{70}$ yield (a) and $C_{70} / C_{60}$ ratio (b) for two sets of flame conditions: ( $\square$ ) 37.5 torr, $C / O=1.00$ and $40 \mathrm{~cm} / \mathrm{s}$; (•) 20 torr, C/O+1.04 and $50 \mathrm{~cm} / \mathrm{s}$ (from chamber surface deposits).

For the high-yield flame, the increased helium concentration marginally reduces the fullerene yield. The $C_{70} / C_{60}$ ratio increases significantly as the helium concentration is increased in the low-yield flame, but changes little in the high-yield flame (Fig. 14, part b). Argon and nitrogen as diluents give lower yields than helium. The highest $C_{60}+C_{70}$ yields as percentage of soot achieved with each gas are $19.6 \%$ with helium, $14.5 \%$ with argon, and $13.8 \%$ with nitrogen. Yields as high as $16.8 \%$ have been produced with no diluent. The relative effectiveness of the three diluents is in the order of their diffusivities, indicative of the diluents' effect on the temperature profile and species concentration profiles.

\section{Identification of New Fullerenes}

Fullerenes in toluene extracts of soot samples from benzene/oxygen flames have been characterized by liquid chromatography with on-line mass spectrometry (LC-MS) techniques, incorporating both positive and negative ion mass spectra obtained by 
26

Table I. LC Relative Retention Times (RRT), Chemical Identifications, Relative Molecular Masses, and Relative Abundances Estimated from Positive-Ion APCI LC-MS (Anacleto et al., 1992b).

\begin{tabular}{|c|c|c|c|c|c|}
\hline \multirow[b]{2}{*}{ RRT } & \multirow[b]{2}{*}{ compound (s) } & \multirow[b]{2}{*}{ Rel.mol.mass } & \multicolumn{3}{|c|}{ Relative Levels } \\
\hline & & & Plame & TFC & MER \\
\hline 1.000 & $C_{60}$ fullerene & 720 & 100 & 100 & 100 \\
\hline 1.105 & $C_{70}$ fullerene & 840 & 20 & 8.0 & 9.5 \\
\hline 0.956 & $\mathrm{C}_{60} \mathrm{O} \quad\left(\mathrm{C}_{60} . \mathrm{CH}_{4}\right)$ & $736 \quad(736)$ & $10(?)$ & $6.4(\mathrm{ND})$ & (ND) $(0.25)$ \\
\hline 0.978 & $\mathrm{C}_{60}$ isomer? & 720 & 61 & ND & ND \\
\hline 1.085 & $C_{70}$ isomer? & 840 & 7.0 & ND & ND \\
\hline 1.174 & $C_{94}$ (2 isomers?) & 1008 & 0.65 & 0.26 & 0.46 \\
\hline 0.878 & $\mathrm{C}_{60} \mathrm{H}_{4}$ & 724 & 0.13 & IND & 0.32 \\
\hline 0.921 & $\mathrm{C}_{60} \mathrm{H}_{2}$ & 722 & 0.38 & ND & 5.0 \\
\hline 0.931 & $\mathrm{C}_{60}\left(\mathrm{CH}_{4}\right)_{2} *$ & 752 & $?$ & ND & ND \\
\hline 0.968 & $\mathrm{C}_{60}\left(\mathrm{C}_{7} \mathrm{H}_{5}\right) *$ & 810 & $?$ & ND & $?$ \\
\hline 1.038 & $\mathrm{C}_{70} \mathrm{O}$ & 856 & 0.88 & $N D$ & ND \\
\hline 1.052 & $\mathrm{C}_{70} \mathrm{H}_{2}$ & 842 & $<0.1$ & $<0.1$ & 0.24 \\
\hline 1.069 & $C_{70} \mathrm{O}$ & 856 & 1.8 & 0.66 & ND \\
\hline 1.073 & $\mathrm{C}_{70} \mathrm{O}$ & 856 & 1.0 & 0.58 & ND \\
\hline 1.094 & $C_{70}$ isomer? & 840 & 2.8 & ND & ND \\
\hline 1.128 & $C_{76}$ & 912 & 0.51 & ND & ND \\
\hline 1.154 & $c_{76}$ & 912 & 0.99 & 0.78 & 0.72 \\
\hline 1.163 & $c_{78^{*}}$ & 936 & $?$ & $?$ & $?$ \\
\hline 1.194 & $C_{90}$ & 1080 & 0.02 & ND & ND \\
\hline 1.225 & $C_{90}$ & 1080 & 0.1 & 0.04 & 0.05 \\
\hline 1.231 & $C_{30}$ & 1080 & 0.05 & $<0.04$ & $<0.05$ \\
\hline 1.234 & $C_{94}$ & 1128 & 0.03 & ND & ND \\
\hline 1.246 & $=$, & 1128 & 0.03 & ND & ND \\
\hline 1.257 & $C_{94}$ & 1128 & 0.03 & $<0.02$ & $<0.02$ \\
\hline
\end{tabular}

? Abundance could not be estimated from LC-MS data: usually detected only in negative ion mode. * Tentative identification only. ND Not Detected. 
atmospheric pressure chemical ionization (APCI). The results have been published (Anacleto et al., 1992a and 1992b) and are sumntarized in Table I. As can be seen in the table, the flame-dfrived fullerenes include, in addition to $C_{60}$ and $C_{70}, C_{76}, C_{84}, C_{90}$ and $C_{94}$, the monoxides of $C_{60}$ and $C_{70}$ and many hydrogen-containing complexes including $\mathrm{C}_{60} \mathrm{H}_{2}, \mathrm{C}_{60} \mathrm{H}_{4}, \mathrm{C}_{70} \mathrm{H}_{2}, \mathrm{C}_{60} \mathrm{CH}_{4}$, which may be $\left[\mathrm{C}_{60}\left(\mathrm{CH}_{2}\right)\left(\mathrm{H}_{2}\right)\right]$ or $\left[\mathrm{C}_{60}(\mathrm{H})\left(\mathrm{CH}_{3}\right)\right]$, as well as tentatively identified $\left.\mathrm{C}_{78}, \mathrm{C}_{60} \mathrm{CH}_{4}\right)_{2}$ and $\mathrm{C}_{60}\left(\mathrm{C}_{7} \mathrm{H}_{6}\right)$.

Some compounds in Table $\bar{i}$ are denoted as questionable isomers, referring to their having a different LC retention time, and therefore a different identity, but the same elemental composition as another, more prevalent, species. The isomer identification is shown as being questionable because the observed LC-MS behavior of these species would also support the hypothesis that the species are weakly bound adducts, e.g. $C_{n} M$, which are stable ion L.C separation but dissociate into moiety $M$ and fullerene $C_{n}$ during ionization for mass spectrometry. The observed mass spectrum would then be that of fullerene $C_{n}$. These apparent isomers or adducts were found to be thermally metastable, converting to the stable fullerene $C_{n}$ in times of order 10 minutes at temperatures around $100^{\circ} \mathrm{C}$ (Anacleto et al., 1992a).

Analysis of the metastable $\mathrm{C}_{60}$ compounds by LC with a more gentle MS technique, namely ionspray mass spectrometry, yielded mass spectra consistent with their identification as fullerene adducts with highly unsaturated moities $\mathrm{C}_{60} \mathrm{C}_{5} \mathrm{H}_{6}, \mathrm{C}_{60} \mathrm{C}_{6} \mathrm{H}_{8}$ and $\mathrm{C}_{60} \mathrm{C}_{7} \mathrm{H}_{10}$ (Anacleto et al., 1993).

Isolation of the apparent $\mathrm{C}_{60} \mathrm{C}_{5} \mathrm{H}_{6}$ compound using preparative HPLC provided a solid, which was golden brown in solution, which cleanly converted to $\mathrm{C}_{60}$ at temperatures over $95, \mathrm{C}$. In order to provide a possible mechanism for formation of this compound, as well as to obtain macroscopic quantities of this reagent, $\mathrm{C}_{60}$ was reacted with cyclopentadiene (Rotello et al., 1993). Dropwise addition of freshly distilled cyclopentadiene in benzene to a solution of $\mathrm{C}_{60}$ in benzene at $20^{\circ} \mathrm{C}$ caused an immediate color change of the snlution, from deep purple to golden brown. Removal of solvent provided a brown solid, which was purified by column chromatography to yield a brown solid identical by HPLC, UV-vis and ${ }^{1} \mathrm{H} N \mathrm{NMR}$ to the previously isolated combustion product.

Proton NMR of the adduct was consistent with the bicyclic Diels-Alder product of $\mathrm{C}_{60}$ and cyclopentadiene. In order to verify this structural assignment, we obtained ${ }^{13} \mathrm{C}$ NMR spectra of the cycloadduct. The presence of 33 lines (with one of double intensity) agrees with the expected $C_{8}$ symmetry of the molecule formed by addition across the $C_{6}-$ $\mathrm{C}_{6}$ ring fusion. ( 34 lines are expected, however one may be obscured by solvent.) The structure thus established is shown in Fig. 15 (Rotello et al., 1993).

Kinetic and thermodynamic properties of cycloaddition-cycloreversion reactions of this and other $\mathrm{C}_{60}$-diene systems, as well as other examples of these processes in combustion science, are currently under investigation. 


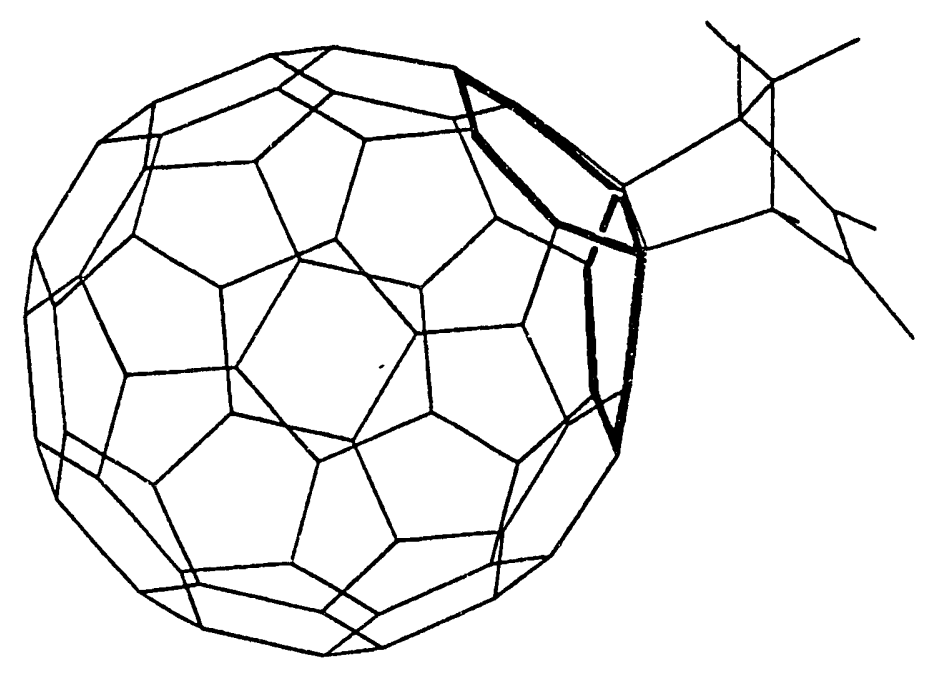

Fig. 15. $C_{60}$-cyclopentadiene adduct $\left(C_{6}-C_{6}\right.$ ring system highlighted for clarity).

\section{Comparison with Soot Formation}

Profiles of fullerenes and soot concentration and temperature in benzene/oxygen/ argon flames at two different $\mathrm{C} / \mathrm{O}$ ratios are shown in (Fig. 16). Fullerenes concentrations, measured by probe sampling, are plotted at the effective flame position represented by the material withdrawn with the probe, here approximated as 2.5 probe orifice diameters upstream of the probe tip. The soot concentration profiles were measured in the previous contract period (McKinnon, 1989) by optical absorption using $1400 \mathrm{~nm}$ wavelength radiation from a tungsten lamp and confirmed in the present contract period by probe sampling and weighing. The temperature profile was measured during both periods by the brightness method.

An indication of the concentration profile of polycyclic aromatic hydrocarbons $(\mathrm{PAH})$ in the two flames represented in Fig. 16 is shown in Fig. 17 as the difference between the absorption attributed to soot and PAH, and that due to soot alone. The analysis is similar in principle to those of Weiner and Harris (1989) and McKinnon (1989). The wavelength regions of strongest absorbance in experimentally measured spectra of $\mathrm{PAH}$, including heavy compounds, extend somewhat beyond, say, $410 \mathrm{~nm}$. The absorbance then falls sharply and becomes negligible at wavelengths well below, say, $1400 \mathrm{~nm}$, and does not rise again until vibrational bands are encountered, beginning at approximately $3 \mu \mathrm{m}$. Also, considering absorption at a given wavelength in premixed sooting flames, the ratio of absorption by PAH to that by soot becomes negligible as distance from the burner increases into the post flame zone where soot concentration greatly exceeds the total PAH concentration. Accordingly, the absorbance of $1400 \mathrm{~nm}$ 

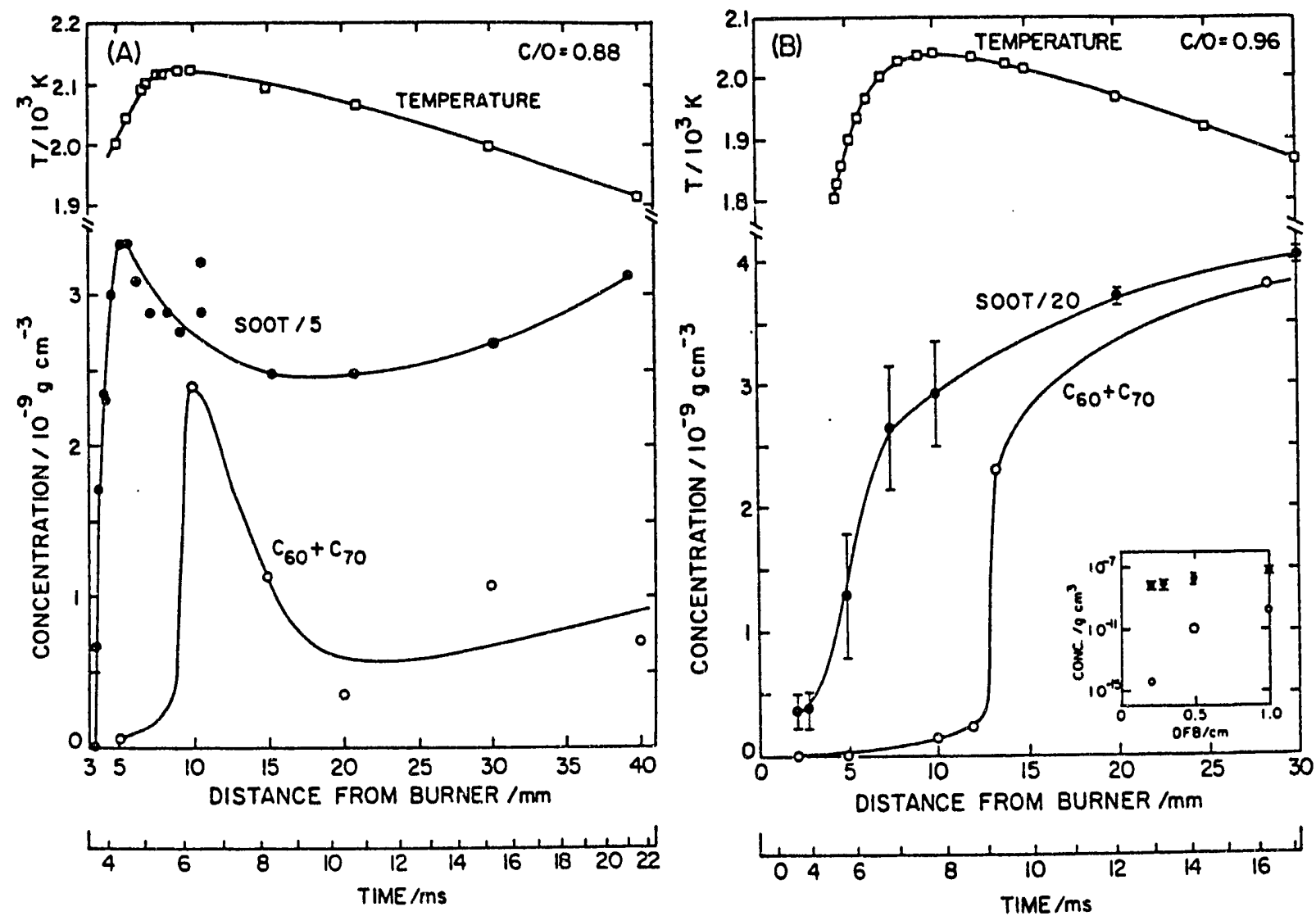

Fig. 16. Profiles of temperature and concentration of fullerenes $C_{60}+C_{70}$ and soot in benzene/oxygen $/ 10 \%$ argon flames at two different $\mathrm{C} / \mathrm{O}$ ratios. Pressure, 40 torr; gas velocity at burner, $25 \mathrm{~cm} / \mathrm{s}(298 \mathrm{~K})$.

at all flame positions and at $410 \mathrm{~nm}$, at large distances from the burner are assumed to be due to soot. The $410 \mathrm{~nm}$ absorbance due to soot, curve (a), is computed as a constant multiple of the absorbance at $1400 \mathrm{~nm}$, the constant being chosen so as to match the 410 $\mathrm{nm}$ profiles at large distances from the burner. The $410 \mathrm{~nm}$ absorbance due to PAH, curve (b), is then obtained by substracting curve (a) from the total absorbance at $410 \mathrm{~nm}$. Since the $1400 \mathrm{~nm}$ absorption data are the source of the soot concentrations shown in Fig. 16, curve (a) in Fig. 17 represents not only soot absorption at $410 \mathrm{~nm}$ (left-hand scale) but also soot concentration (right-hand scale). Although the quantitative relationship between $\mathrm{PAH}$ absorbance at $410 \mathrm{~nm}$ and concentration is not well established, the concentration profiles indicated by curves $(b)$ and the right-hand scales of Fig. 17 are similar, in terms of both the magnitude and location of the peaks, to the profiles of methylene chloride soluble material $(\sim 130$ to $900 \mathrm{~g} / \mathrm{mol})$ measured by probe sampling. 

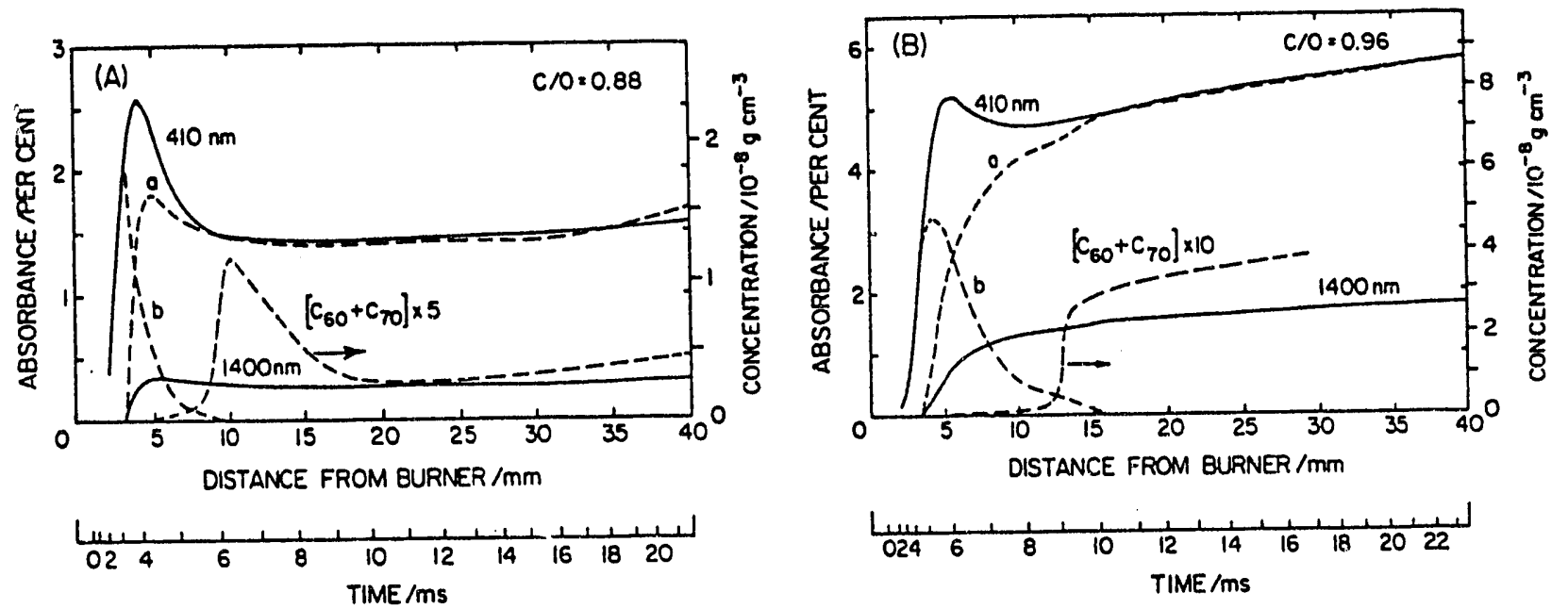

Fig. 17. Optical absorption profiles at two different wavelengths and $C_{60}+C_{70}$ concentration profile in benzene/oxygen $/ 10 \%$ argonf flames at two different $\mathrm{C} / \mathrm{O}$ ratios. Pressure, 40 torr; gas velocity at burner, $25 \mathrm{~cm} / \mathrm{s}(298 \mathrm{~K})$. Curve (a), indicative of contribution of soot to absorption at $410 \mathrm{~nm}$, is absorbance at $1400 \mathrm{~nm}$ multiplied by factor of 5.28 (A) or 3.26 (B). Curve (b), indicative of contribution of PAH to abosrption at $410 \mathrm{~nm}$, is vertical displacement between absorbance at $410 \mathrm{~nm}$ and curve (a). $\mathrm{C}_{60}+\mathrm{C}_{70}$ curves, from Fig. 16.

Evidence of formation and subsequent destruction can be seen at $\mathrm{C} / \mathrm{O}=0.88$ (Fig. 17, part A) in the profiles of PAH, curve (b), soot, curve (a), and fullerenes $C_{60}+C_{70}$. Rapid PAH decay and rapid soot formation occur together from 3 to $5 \mathrm{~mm}$ from the burner, and a subsequent period of net soot decay occurs from 5 to $10 \mathrm{~mm}$ when the $\mathrm{PAH}$ and benzene concentrations are no longer large enough to sustain a rate of soot growth in excess of the destruction rate. Fullerenes in this flame form after the main stage of soot formation, during the subsequent stage of net soot destruction. The location of the main formation of fullerene precursors is not indicated by these data alone, which reveal only the appearance of completed structures. Clearly, an intermediate flame position or residence time (i.e., $10 \mathrm{~mm}$ or $6.2 \mathrm{~ms}$ ) would be optimum for fullerenes production under these conditions.

At $\mathrm{C} / \mathrm{O}=0.96$ (Fig. 17, part B), only the PAH exhibit both formation and destruction stages, the soot and fullerenes concentrations increasing monotomically with distance or time. As benzene and PAH are depleted in this richer flame, the soot growth reactions, which also include $\mathrm{C}_{2} \mathrm{H}_{2}$ as reactant, remain faster than destruction. Similarly, the 
synthesis of fullerenes remains faster than fullerenes destruction throughout the flame. As in the other flame, the formation of fullerenes $C_{60}$ and $C_{70}$ occurs after soot formation has progressed to a substantial concentration. The early increase in concentration seen in these profiles reflects mainly upstream diffusion, and the peak rate of net: formation occurs somewhat downstream of the steep rise in the concentration profile. Nevertheless, comparison of the $C_{60}+C_{70}$ and soot profiles reveals that the chemistry of fullerenes formation lags that of soot formation by several milliseconds under the conditions of Fig. 16.

These observations are qualitatively consistent with the known behavior of the competing growth and destruction reactions in the case of soot precursors, and the expected difference between the reaction rates of these species and those of fullerene precursors when both are in the presence of the same growth and destruction reactants. Given the curved and hence strained configuration of fullerene intermediates, these species are expected to grow less rapidly than the large planar PAH envisioned to be soot precursors. For the same reason, fullerene intermediates are expected to be more reactive than the soot precursors in the destruction reactions. However, once fullerene molecules have formed, they are assumed to be less reactive than soot precursors, owing to the absence of edge atoms in the fullerenes. Therefore, in a given flame, the net growth rate of fullerene precursors would be expected to be less than that of soot precursurs, consistent with fullerenes appearing well after the onset of soot formation in sooting flames. Also, the lower reactivity of completed fullerene structures as compared to the reactivity of soot would indicate that fullerenes, once formed, could remain present even under conditions where soot would be destroyed. Such a situation seems to exist in the nonsooting $\mathrm{C} / \mathrm{O}=0.72$ flame mentioned above. This flame was sampled at the position of the maximum concentration of species heavier than 700 $\mathrm{g} /$ mole, which is the position at which the onset of soot formation would occur if the $\mathrm{C} / \mathrm{O}$ ratio were increased by only $5 \%$. Thus soot formation is impending at the position sampled, but does not occur because, as distance from the burner increases beyond this position, the rate of destruction of the soot precursors exceeds the growth rate. The observation of fullerenes $C_{60}$ and $C_{70}$ in this flame shows that these species can form and attain recoverable quantities under conditions where the accompanying high molecular weight soot precursors, although exhibiting larger peak concentrations than the observed fullerenes concentration, are unable to generate soot. Trends in the data reflect similarities but also substantial differences between the formation mechanisms of fullerenes as compared to those of soot. Both formation processes are believed to involve many of the same types of reactions, e.g., growth in small steps by addition of $\mathrm{C}_{2} \mathrm{H}_{2}$ and other small species and in large steps by reactions between polycyclic compounds, competition between growth and destruction reactions, and extensive involvement of radical sites at edge carbons in the growing polycyclic structures. The different trends exhibited by the two processes may reflect different sensitivities to the different reactions, a consequence of the very different structures being formed. Soot formation does not involve the development of curved or bowl-shaped structures as required for fullerenes, nor would these curved structures permit the rapid stacking required in the reactive coagulation of the relatively flat sheet-like soot precursors. That the very special fullerene structures are formed in flames, and that the formation occurs 
in the presence or absence of soot formation, provide new insight into the reactions important to both processes.

\section{Fullerenes Formation Mechanism}

Fullerene formation is seen as a subset of the molecular weight growth processes occurring in flames, fullerenes themselves being seen as a limiting type of PAH. The differences between fullerenes and planar PAH are: 1) fullerenes are curved as the result of pentagons incorporated into their structures, and 2) fullerenes are free of hydrogen. Also, unlike soot, fullerenes have well-defined structures, with specific placements of hexagons and pentagons. The fullerene formation sequence branches off from the planar PAH growth sequence when internal pentagons occur within the PAH structure. Also, fullerene formation has a specific endpoint, namely the completion of the closed-cage structure.

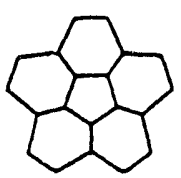

a)

b)

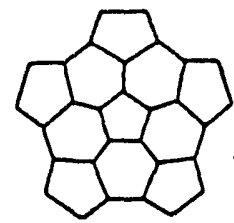

c)

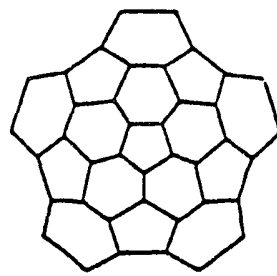

d)

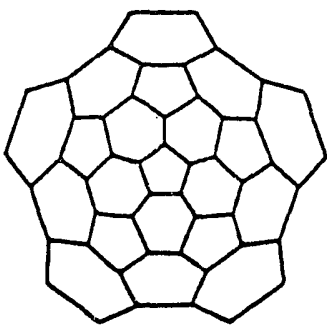

Fig. 18. Proposed fullerene precursors: a) $\mathrm{C}_{20} \mathrm{H}_{10}$, b) $\mathrm{C}_{30} \mathrm{H}_{10}$, c) $\mathrm{C}_{40} \mathrm{H}_{10}$, d) $\mathrm{C}_{50} \mathrm{H}_{10}$.

The proposed formation mechanism starts with fluoranthene $\left(\mathrm{C}_{16} \mathrm{H}_{10}\right)$, the smallest $\mathrm{PAH}$ which has a pentagon in which each atom is part of an adjacent hexagon. The growth sequence proceeds via net $C_{2}$ addition through intermediates of $C_{5 v}$ symmetry (Fig. 18): $\mathrm{C}_{20} \mathrm{H}_{10}$ (corannulene), $\mathrm{C}_{30} \mathrm{H}_{10}, \mathrm{C}_{40} \mathrm{H}_{10}$, and $\mathrm{C}_{50} \mathrm{H}_{10}$. Types of reactions occurring during this stage of growth are: $\mathrm{H}$-abstraction, $\mathrm{C}_{2} \mathrm{H}_{2}$ addition, and ring closing $/ \mathrm{H}$ elimination. These $C_{5 v}$ intermediates can dimerize and form closed cages via successive $\mathrm{H}$-abstruction and cyclization/H-elimination. $\mathrm{C}_{50} \mathrm{H}_{10}$ can also directly form $\mathrm{C}_{60}$ through the above types of reactions and intramolecular rearrangement. Only structures obeying the isolated pentagon rule are considered. Direct $\mathrm{C}_{70}$ formation proceeds from $\mathrm{C}_{50} \mathrm{H}_{10}$ via $\mathrm{C}_{60} \mathrm{H}_{10}$, then through the cage closing process described above.

Thermodynamic properties for all the intermediates in the formation mechanisms were estimated via group additivity. A group for curved junctions of two hexagons and 
one pentagon was obtained from the properties of $\mathrm{C}_{60}$. Experimental $\Delta \mathrm{H}_{\mathrm{f}}$ and $\Delta \mathrm{H}_{\text {sub }}$ were used, while $C_{p}$ and $\Delta S$ were taken from previous work using calculated vibrational frequencies. Rate coefficients used for the above types of reactions are those for analogous PAH reactions.

Simulations of flat flames (plug-flow systems with axial diffusion) are routinely performed, but are computationally intensive (of order 10 CRAY cpu hours). Also, predictions of species important in the fullerene formation mechanism $\left(\mathrm{H}, \mathrm{H}_{2}, \mathrm{C}_{2} \mathrm{H}_{2}\right.$, small $\mathrm{PAH}$ ) based on existing flame models are not sufficiently reliable to test fullerene formation based on these species. The present work models the flame as a plug flow reactor, tentatively neglecting diffusion. Input values for $\mathrm{H}, \mathrm{H}_{2}, \mathrm{C}_{2} \mathrm{H}_{2}$, and the initial fullerene precursor (fluoranthene) are taken from flat flame data.

Plug flow simulations using the entire mechanism show yields of fullerenes $\mathrm{C}_{60}$ and $\mathrm{C}_{70}$ within plausible time scales. For a rich $(\mathrm{C} / \mathrm{O}$ ratio $=0.88) 40$ Torr benzene-oxygen flame, the fractional yield of fullerenes from an initial input of fluoranthene can be approximated by $\exp \left(-k^{*}\left(t-\tau^{*}\right)\right)$, with $k^{*} \approx 340 \mathrm{~s}^{-1}$ and $\tau^{*} \approx 2.3 \mathrm{~ms}$. These parameters are extremely sensitive to input values for concentrations of $\mathrm{H}, \mathrm{H}_{2}$ and $\mathrm{C}_{2} \mathrm{H}_{2}$, and for the rate coefficients. It is also found that only of order $10^{-6}$ of the fullerenes are formed via the dimerization route, due to low concentrations of the $C_{5 v}$ intermediates.

The proposed mechanism gives plausible times for forming fullerenes in flames, given the uncertainties in the input parameters and the simplifications made in modeling the flame structure. The proposed chemistry is expected to be analogous to that of fullerene formation in carbon vapor systems, with the exception of the need to eliminate hydrogen from the growing carbon structures.

\section{CONCLUSIONS}

\section{Aromatics Oxidation Conclusions}

The role given phenyl by the Jackson and Laurendeau model is not consistent with the data of this project. Either the phenyl intermediate is not dominant, or the phenyl destruction pathway is not adequately modeled.

Significant differences between benzene destruction in rich $\mathrm{H}_{2}-\mathrm{O}_{2}$ flames and in rich $\mathrm{C}_{6} \mathrm{H}_{6}-\mathrm{O}_{2}$ flames are indicated by differences in relative concentration of phenol and cyclopentadiene in the two flames.

Several commonly-used $\mathrm{H}_{2}-\mathrm{O}_{2}$ combustion models are found to be inadequate to model $\mathrm{O}_{2}$ concentration in rich $\mathrm{H}_{2}-\mathrm{O}_{2}$-trace $\mathrm{C}_{6} \mathrm{H}_{6}$ flames. The problem may lie in the $\mathrm{O}$ atom chemistry. 


\section{Soot Formation Conclusions}

The measured rate of soot particle nucleation supports the hypothesis that the inception of soot particles is the net effect of growth by reactive coagulation of high molecular weight $\mathrm{PAH}$ and destruction through $\mathrm{OH}$ attack. The predicted rate of growth through $\mathrm{C}_{2} \mathrm{H}_{2}$ addition is significantly slower than that corresponding to the measured rate of soot nucleation .

The measured rate of increase of soot mass subsequent to the particle inception stage is consistent with the hypothesis that carbon is added to the soot particles through reactions with both $\mathrm{C}_{2} \mathrm{H}_{2}$ and $\mathrm{PAH}$.

Soot structure observed by high resolution transmission electron microscopy indicates the roughly spherical units or spherules of the soot aggregates consist of smaller particles, i.e., the structure appears to be that of paricles within particles. If confirmed by more detailed measurements and quantitative image analysis, this structure would be consistent with the growth mechanism inferred from the analysis of $\mathrm{C}_{2} \mathrm{H}_{2}$ and $\mathrm{PAH}$ data, the smaller particles being the result of the reactive coagulation of heavy $\mathrm{PAH}$ and the larger spherules representing the coagulation of the smaller particles in parallel with mass deposition from $\mathrm{PAH}$ and $\mathrm{C}_{2} \mathrm{H}_{2}$.

\section{Fullerene Formation Conclusions}

Fullerenes can be synthesized in substantial quantities in flames. Most of this research has been performed with subatmospheric pressure, laminar, premixed flames of benzene and oxygen, with or without an inert diluent gas, but acetylene has also been used successfully.

The largest yields of fullerenes are produced in sooting flames, but not under the most heavily sooting conditions. The largest conversion of carbon to soot is about $12 \%$ in fullerene forming flames, but the largest yields and production rates of fullerenes are observed when about 2-3\% of the carbon is converted to soot. Small yields of fullerenes are formed in nonsooting flames near the critical conditions for impending soot formation.

The largest yield of $\mathrm{C}_{60}+\mathrm{C}_{70}$ as a percentage of soot is $20 \%$, observed at a pressure of 37.5 torr, a C/O atomic ratio of 0.959 and $25 \%$ helium. The largest $C_{60}+C_{70}$ yield on a basis of percentage of carbon fed is about $0.5 \%$, and the largest $\mathrm{C}_{60}+\mathrm{C}_{70}$ production rate $(\mathrm{g} / \mathrm{hr})$ was observed at a pressure of 69 torr, a C/O ratio of 0.989 and $25 \%$ helium.

The $\mathrm{C}_{70} / \mathrm{C}_{60}$ molar ratios observed under different flame conditions are in the range of $0.26-8.8$, compared to $0.02-0.18$ for the graphite vaporization method. The ratio is typically 1.5 to 1.8 for the flame conditions of largest $C_{60}+C_{70}$ production rates and yields. The largest values of this ratio are observed under conditions where the fullerene yields and production rates are relatively low. 
Flame derived fullerenes also include, in addition to $\mathrm{C}_{60}$ and $\mathrm{C}_{70}, \mathrm{C}_{60} \mathrm{O}, \mathrm{C}_{70} \mathrm{O}, \mathrm{C}_{76}, \mathrm{C}_{84}$ $\mathrm{C}_{90}$ and $\mathrm{C}_{94}$ and many hydrogen-containing complexes such as $\mathrm{C}_{60} \mathrm{H}_{2}, \mathrm{C}_{60} \mathrm{H}_{4}, \mathrm{C}_{70} \mathrm{H}_{2}$ $\left[\mathrm{C}_{60}\left(\mathrm{CH}_{2}\right)\left(\mathrm{H}_{2}\right)\right]$ or $\left[\mathrm{C}_{60}(\mathrm{H})\left(\mathrm{CH}_{3}\right)\right], \mathrm{C}_{60} \mathrm{C}_{5} \mathrm{H}_{6}, \mathrm{C}_{60} \mathrm{C}_{6} \mathrm{H}_{8}$ and $\mathrm{C}_{60} \mathrm{C}_{7} \mathrm{H}_{10}$. The last three species are thermally unstable. The structure of the $\mathrm{C}_{60} \mathrm{C}_{5} \mathrm{H}_{6}$ compound is that of the Diels-Alder adduct of $\mathrm{C}_{60}$ and cyclopentadiene.

Fullerenes first appear after soot formation has progressed to a substantial concentration, thereby indicating that fullerenes formation chemistry tends to lag that of soot formation.

Fullerenes formation in flames is a molecular weight growth process analogous to the formation of PAH and soot but involving curved and hence strained structures. A kinetically plausible mechanism of $C_{60}$ and $C_{70}$ fullerenes formation in flames has been constructed based on the types of reactions already used in describing PAH and soot growth, but including intramolecular rearrangements and other reactions needed to describe the evolution of the unique fullerene structures.

\section{ACKNOWLEDGEMENTS}

We are grateful to M.K. Chung, A.B. Chwang, A.G. Dietz III, L.M. Giovane, D.G. Goldenson, M.E. Johnson, R.J. Juba, Jr., A.L. Lafleur, Y. Makarovsky, R. Marino, J.A. Marr, S. Mitra, M.D. Nyström, V.M. Rotello, and L.W. Theiss for valuable collaboration and/or laboratory work.

\section{REFERENCES}

Ajie, H., Alvarez, M.M., Anz, S.J., Beck, R.D., Diederich, F., Fostiropoulos, K., Huffman, D.R., Krätschmer, W., Rubin, Y., Schriver, K.E., Sensharma, D., and Whetten, R.L. (1990). J. Phys. Chem., 94, 8630.

Anacleto, J.F., Pereault, H., Boyd, R.K., Pleasance, S., Quilliam, M.A., Sim, P.G., Howard, J.B., Makarovsky, Y., and Lafleur, A.L. (1992a). Rapid Communications in Mass Spectrometry, 6, 214.

Anacleto, J.F., Boyd, R.K., Pleasance, S., Quilliam, M.A., Howard, J.B., Lafleur, A.L., and Makarovsky, Y. (1992b). Canad. J. Chem., 70, 2558.

Anacleto, J.F., Quilliam, M.A., Boyd, R.K., Howard, J.B., Lafleur, A.L., and Yadav, $\mathrm{T}$ (1993). Rapid Communications in Mass Spectrometry (in press).

Biordi, J.C., Lazzara, C.P., and Papp, J.F. (1974). Combustion and Flame, $23,73$.

Bittner, J.D. (1981). Ph.D. Thesis, MIT. 
Bittner, J.D. and Howard, J.B. (1981). Eighteenth Symposium (International) on Combustion, p. 1105.

Chevalier, C. and Warnatz, J. (1991). A.C.S. Div. Fuel Chem. Preprints, 36(4), 1486.

Emdee, J.L., Brezinsky, K. and Glassman, I. (1992). J. Phys. Chem., 96, 2151.

Fristrom, R.M. and Waternberg, A.A. (1965). Flame Structure, McGraw-Hill, New York.

Howard, J.B., McKinnon, J.T., Shandross, R.A., and Pope, C.J. (1990). "Aromatics Oxidation and Soot Formation in Flames", Progress Report, Aug. 15, 1987-Aug. 14, 1990, Contract No. DE-FG02-84ER13282, U.S.D.O.E., Office of Energy Research, Office of Basic Energy Sciences, Division of Chemical Sciences.

Howard, J.B., McKinnon, J.T., Makarovsky, Y., Lafleur, A.L., and Johnson, M.E. (1991). Nature, 352, 129.

Howard, J.B., McKinnon, J.T., Johnson, M.E. Makarovsky, Y., and Lafleur, A.L. (1992a). J. Phys. Chem., 96, 6657.

Howard, J.B., Lafleur, A.L., Makarovsky, Y., Mitra, S., Pope, C.J., and Yadav, T. (1992b). Carbon, 30, 1183.

Jackson, M.C. and Laurendeau, N.M. (1987). Energy \& Fuels, 1, 405.

Kee, R.J., Rupley, F.M. and Miller, J.A. (1987). SANDIA Report SAND87-8215.

Krätschmer, W., Lamb, L.D., Fostiropoulos, K., and Huffman, D.R. (1990). Nature, 347, 354.

Kroto, H.W., Heath, J.R., O'Brien, S.C., Curl, R.F., and Smalley, R.E. (1985). Nature, 318, 162.

Lafleur, A.L., Monchamp, P.A., Plummer, E.F., and Kruzel, E.L. (1986). Analytical Letters, 19, 2013.

Lazzara, C.P., Biordi, J.C., and Papp, J.F. (1973). Combustion and Flame, 21, 371.

Lee, S.C. and Tien, C.L. (1981). Eighteenth Symposium (International) on Combustion, p. 1159.

McKinnon, J.T. (1989). Ph.D. Thesis, MIT.

McKinnon, J.T. and Howard, J.B. (1992). Twenty-Fourth Symposium (International) on Combustion, The Combustion Institute, Pittsburgh, p. 965. 
Miller, J.A., Mitchell, R.E., Smooke, M.D. and Kee, R.J. (1983). Nineteenth Symposium (International) on Combustion, The Combustion Institute, Pittsburgh, p. 181.

Peeters, J. and Vinckier, C. (1975). Fifteenth Symposium (International) on Combustion, The Combustion Institute, Pittsburgh, p. 969.

Rotello, V.M., Howard, J.B., Yadav, T., Conn, M.M., Viani, E., Giovane, L.M., and Lafleur, A.L. (1993). Tetrahedron Letters (in press).

Shandross, R.A., Longwell, J.P. and Howard, J.B. (1991). Combustion and Flame, 85, 282.

Taylor, R., Hare, J.P., Abdul-Sada, A.K., and Kroto, H.W. (1990). J. Chem. Soc., Chem. Commun., 1423.

Warnatz, J. (1983). Combust. Sci. Tech., 34, 177.

Warnatz, J. (1984). Chapter 5 in Combustion Chemistry, W.C. Gardiner, Ed., SpringerVerlag, New York.

Weiner, A.M. and Harris, S.J. (1989). Combust. Flame, 77, 261.

Westmoreland, P.R. (1986). Ph.D. Thesis, MIT.

\section{PUBLICATIONS FROM THIS PROJECT (1990-1993)}

McKinnon, J.T., and Howard, J.B.: "Application of Soot Formation Model: Effects of Chlorine", Combustion Science and Technology, 74, 175-197 (1990).

Howard, J.B.: "Radical Sites as Active Sites in Carbon Addition and Oxidation Reactions at High Temperatures", Fundamental Issues in Control of Carbon Gasification Reactivity, J. Lahaye and P. Ehrburger, Eds., pp. 377-382, Kluwer Academic Publishers, 1991.

Howard J.B.: "Carbon Addition and Oxidation Reactions in Heterogeneous Combustion and Soot Formation", Twenty-Third Symposium (International) on Combustion, The Combustion Institute, Pittsburgh, 1107-1127 (1991).

Shandross, R.A., Longwell, J.P. and Howard, J.B.: "Noncatalytic Thermo- couple Coating for Low-Pressure Flames", Combustion and Flame, 85, 282-284 (1991).

Howard, J.B., McKinnon, J.T., Makarovsky, Y., Lafleur, A.L., and Johnson, M.E.: "Fullerenes $C_{60}$ and $C_{70}$ in Flames", Nature, 352, 139-141 (1991). 
Anacleto, J.F., Pereault, H., Boyd, R.K., Pleasance, S., Quilliam, M.A., Sim, P.G., Howard, J.B., Makarovsky, $Y$., and Lafleur, A.L.: " $C_{60}$ and $C_{70}$ Fullerene Isomers Generated in Flames. Detection and Verification by Liquid/Mass Spectrometry Analyses", Rapid Communications in Mass Spectrometry, 6, 214-220 (1992).

Howard, J.B., McKinnon, J.T., Johnson, M.E. Makarovsky, Y., and Lafleur, A.L.: "Production of $\mathrm{C}_{60}$ and $\mathrm{C}_{70}$ Fullerenes in Benzene-Oxygen Flames", J. Phys. Chem., 9, 6657-6662 (1992).

Howard, J.B., Lafleur, A.L., Makarovsky, Y., Mitra, S., Pope, C.J., and Yadav, T.: "Fullerenes Synthesis in Combustion", Carbon, 30, 1183-1201 (1992).

Mitra, S., Pope, C.J., Gleason, K.K., Makarovsky, Y., Lafleur, A.L., and Howard, J.B.: "Synthesis of Fullerenes $\left(C_{60}\right.$ and $\left.C_{70}\right)$ by Combustion of Hydrocarbons in a Flat Flame Burner", Mat. Res. Soc. Symp. Proc., 270, 149-154 (1992).

Anacleto, J.F., Boyd, R.K., Pleasance, S., Quilliam, M.A., Howard, J.B., Lafleur, A.L., and Makarovsky, Y.: "Analysis of Minor Constituents in Fullerene Soots by LC-MS using a Heated Pneumatic Nebuliser. Interface with Atmospheric Pressure Chemical Ionization, Canad. J. Chem., 70, 2558-2568 (1992).

McKinnon, J.T. and Howard, J.B.: "The Roles of PAH and Acetylene in Soot Nucleation and Growth", Twenty-Fourth Symposium (International) on Combustion, The Combustion Institute, Pittsburgh, 965-971 (1992).

Howard, J.B.: "Fullerenes Formation in Flames", Twenty-Fourth Symposium (International) on Combustion, The Combustion Institute, Pittsburgh, 933-946 (1992).

Rotello, V.M., Howard, J.B., Yadav, T., Conn, M.M., Viani, E., Giovane, L.M., and Lafleur, A.L.: "Isolation of Fullerene Products from Flames: Structure and Synthesis of the $C_{60}$-Cyclopentadiene Adduct", Tetrahedron Letters, 34, 1561-1562 (1993).

Anacleto, J.F., Quilliam, M.A., Boyd, R.K., Howard, J.B., Lafleur, A.L., and Yadav, T.: "Charge-Transfer Ionspray LC-MS Analyses of Fullerenes and Related Compounds trom Flame-Generated Materials", Rapid Communications in Mass Spectrometry, 7, 229-234 (1993). 

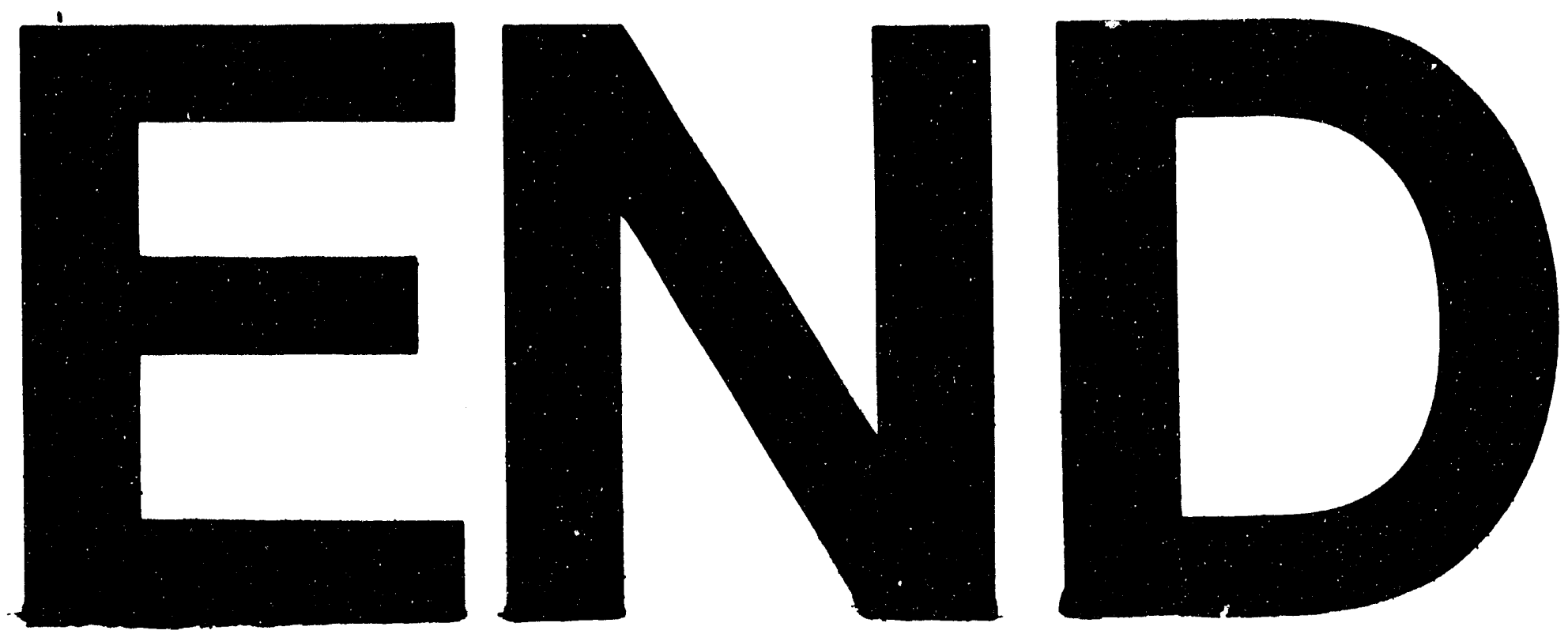

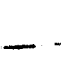

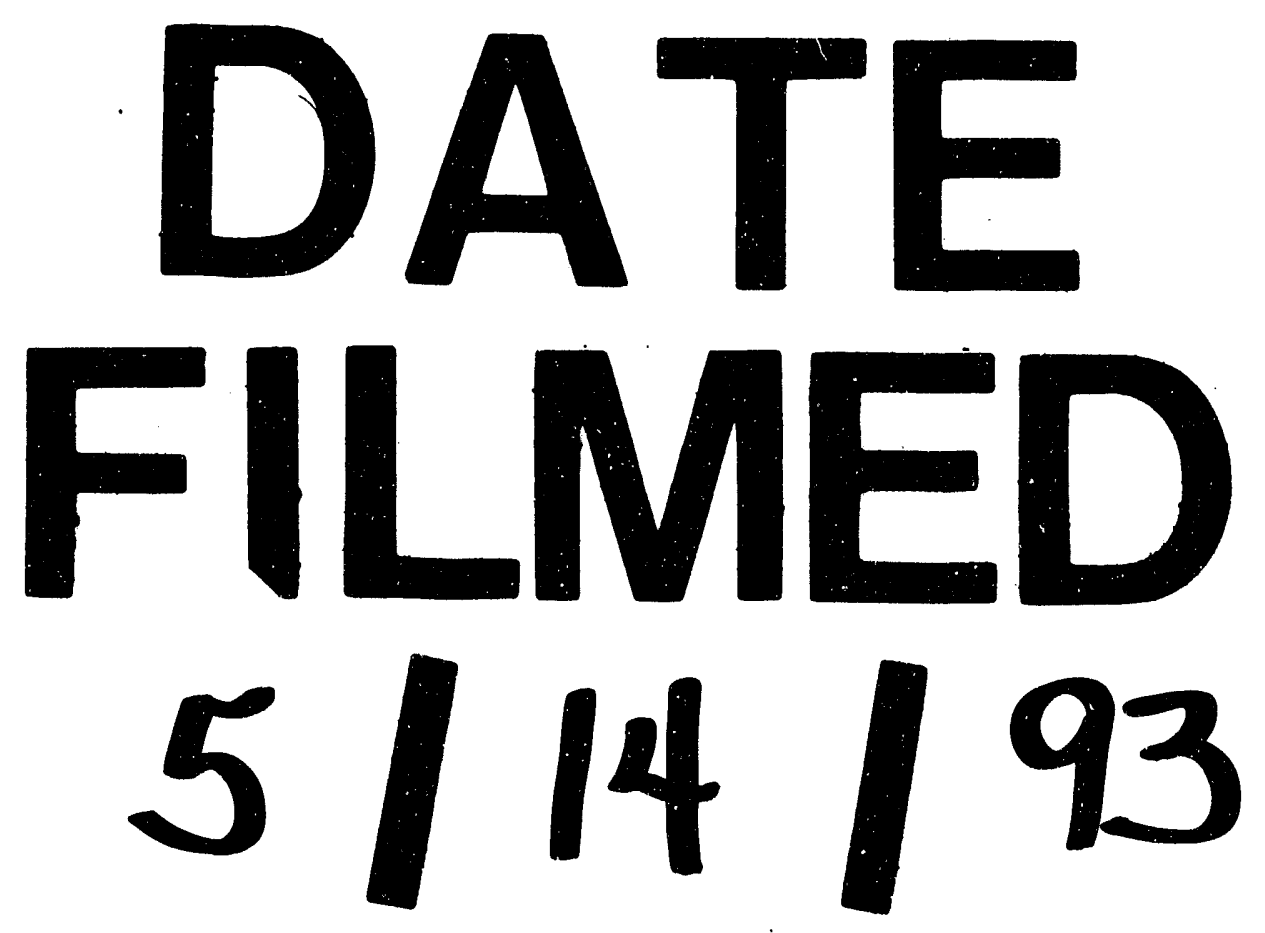


